\title{
An Empirical Validation of a Unified Model of Electronic Government Adoption (UMEGA)
}

\section{Yogesh K. Dwivedi*}

Emerging Markets Research Centre (EMaRC)

School of Management

Swansea University Bay Campus

Fabian Way, Swansea

SA1 8EN, Wales, UK

Tel: +44 (0) 1792602340

E-mail: ykdwivedi@gmail.com

*Corresponding Author

\section{Nripendra P. Rana}

Emerging Markets Research Centre (EMaRC)

School of Management

Swansea University Bay Campus

Fabian Way, Swansea

SA1 8EN, Wales, UK

E-mail: nrananp@gmail.com

\section{Marijn Janssen}

Section of Information \& Communication Technology

Faculty of Technology, Policy, and Management

Delft University of Technology

E-mail: M.F.W.H.A.Janssen@tudelft.nl

\section{Banita Lal}

Nottingham Business School

Nottingham Trent University, UK

E-mail: banita.lal@ntu.ac.uk

\section{Michael D. Williams}

School of Management

Swansea University Bay Campus

Fabian Way, Swansea

SA1 8EN, Wales, UK

E-mail: m.d.williams@swansea.ac.uk

\section{Marc Clement}

School of Management

Swansea University Bay Campus

Fabian Way, Crymlyn Burrows

Swansea, SA1 8EN, Wales, UK

E-mail:r.m.clement@swansea.ac.uk 


\title{
Highlights
}

- Nine adoption models are reviewed

- 29 different adoption constructs are identified

- The UMEGA outperforms all other models for e-government

- Government context should be taken into account

- The UMEGA is simpler to use and has a better explanatory power than the UTAUT

\begin{abstract}
In electronic government (hereafter e-government), a large variety of technology adoption models are employed, which make researchers and policymakers puzzled about which one to use. In this research, nine well-known theoretical models of information technology adoption are evaluated and 29 different constructs are identified. A unified model of e-government adoption (UMEGA) is developed and validated using data gathered from 377 respondents from seven selected cities in India. The results indicate that the proposed unified model outperforms all other theoretical models, explaining the highest variance on behavioral intention, acceptable levels of fit indices, and significant relationships for each of the seven hypotheses. The UMEGA is a parsimonious model based on the e-government-specific context, whereas the constructs from the original technology adoption models were found to be inappropriate for the e-government context. By using the UMEGA, relevant e-government constructs were included. For further research, we recommend the development of egovernment-specific scales.
\end{abstract}

Keywords: E-government, Unified model, Adoption, Diffusion, Social cognitive theory, Context, India, UMEGA

\section{Introduction}

Citizens are apt to be more skeptical and cynical toward governments. At the same time, they are demanding more from the governments and want to be able to direct input on public issues that affect them (Scott, 2006). These developments pose higher requirements on public organizations to develop their e-government efforts.

E-government can be defined as the delivery of government information and services to citizens through the Internet (as the Internet is one of the preconditions to the acceptance and use of e-government services) or other digital means (Joseph, 2013; West, 2004). It provides citizens with convenient access to such information and services (Schaupp \& Carter, 2010), the ability to search and acquire them at their own convenience without the restriction of 
geography (Schaupp et al., 2010; West, 2008), and the ability to participate in open government (McDermott, 2010). The interactive nature of e-government provides benefits for citizens and bureaucrats alike (Luna-Reyes et al., 2012; West, 2008).

On the one hand, e-government can provide a number of benefits to its stakeholders, including reducing corruption; delivering more-accountable, -transparent, and -easily accessible public services; the reduction of administrative burdens; the cost-effective delivery of many types of public services, including online transactions; the integration of services; promoting e-democracy; providing a citizen-oriented focus; prevailing over the social divide; and faster adaptation to meet citizens' requirements (Akman et al., 2005; Hackney et al., 2007; Huang \& Bwoma, 2003; Tolbert \& Mossberger, 2006; Watson \& Mundy, 2001). On the other hand, governments face a number of challenges (e.g. infrastructural issues, lack of financial resources, lack of political support, lack of organizational skills and effective communication, and a lack of training and capacity building) in implementing e-government (Al-Sebie \& Irani, 2005; Gauld et al., 2010), and these challenges are reflected in the low deployment rate of e-government around the world (Nkohkwo \& Islam, 2013; Venkatesh, Chan, \& Thong, 2012). About $98 \%$ of the countries in the world have developed government websites, with less than one-third providing transactional services, such as online form submission (Taheri \& Mirghiasi, 2016; United Nations, 2010). The Online Permanent Account Number (PAN) card registration system (OPCRS) is one such e-government system, which provides transactional services to the citizens of India.

Realizing the significant benefits provided by e-government, particularly to citizens, a number of empirical studies have examined the adoption of such systems (e.g. Belanger \& Carter, 2008; Horst et al., 2007; Hung et al., 2009; Lean et al., 2009; Wang \& Liao, 2008; Wang \& Shih, 2009). However, these studies have largely employed alternative models of IT adoption, such as the technology acceptance model (TAM), the theory of planned behavior 
(TPB), the diffusion of innovation (DOI), and the unified theory of acceptance and use of technology (UTAUT) independently or in combination to understand citizens' reluctance or slow adoption of various e-government services. As most theories used in prior research of egovernment adoption have used conventional information systems (ISs) constructs, they tend to be criticized for not taking into account constructs representing e-government-specific perspectives, such as trust, risk, security, transparency, and privacy. Businesses and governments consider matters like privacy differently. Companies represent their own interests, related to making profit, whereas the government should represent societal interests. This influences perceptions, and the aforementioned constructs become invariably significant in the context of e-government research. Furthermore, emphasizing these aspects is often viewed as promoting public values that should be considered by the government.

A key difference between commercial organizations entering the e-commerce age and governments implementing e-government is the mandatory, rather than voluntary, nature of relationships. Government agencies may be required by law to share information with other agencies or with the citizenry, intensifying the need for trust in e-government if it is to succeed. Moreover, another aspect germane to the discussion of trust (or risk) in egovernment emerges from citizens' strong opinions about political entities. Citizens have strong opinions about the morality of political parties and individual politicians. For a process that includes monetary transactions and information exchanges to be accepted, it must be removed from the political arena in the minds of the citizens - they must trust the online processes regardless of which party is in power at the time (Warkentin et al., 2002). Similarly, while interacting with the e-government services, citizens provide written information through technological interfaces and as a result feel a lack of privacy. Academic research in e-government (e.g. Al-Adawi et al., 2005; Palmer, 2002) has shown that security and privacy are among the predominant factors for e-government adoption. Likewise, other 
research studies (Bertot et al., 2012; Bonsón et al., 2012) have highlighted the potential contribution of the Internet to enhancing the transparency and openness of public-sector entities (through e-government), which can promote citizens' trust in governments. For example, using content syndication and social media platforms to bring the government activities and agenda closer to citizens and to provide citizens with opportunities to participate in decision- and policy-making are good ways of promoting transparency through online systems (Bonsón et al., 2012). A number of studies (e.g. Kim et al., 2008) have explored trust and risk in e-commerce, but few studies (e.g. Belanger \& Carter, 2008) have empirically validated their roles in e-government. This gap in the literature is noticeable in the empirical research on e-government adoption (Nielsen, 2016). Recognizing the limited proficiency of IS concepts, which are largely used in exploring technology adoption and are incapable of considering the complexities surrounding e-government, there is a need for a theory-building exercise as an independent form of research in e-government adoption, using fundamental IS / information technology (IT) theories/models and concepts (Dwivedi et al., 2012; Rana et al., 2016; 2015a).

As a number of studies (e.g. Coursey \& Norris, 2008; Chan et al., 2011; Dwivedi et al., 2012; Hardy \& Williams, 2011; Heeks \& Bailur, 2007; Norris \& Lloyd, 2006) have acknowledged the theoretical fragmentation or lack of theoretical development and rigor in the egovernment adoption research, this study takes a step toward formulating a UMEGA and demonstrates how the proposed e-government-specific unified model performs better than other models of IS/IT adoption, including the UTAUT itself. This aim is accomplished by examining the performance of nine adoption models using empirical data and, based on this, formulating a UMEGA and testing its performance. The selection of these models is largely based on their frequent use in examining e-government adoption in various contexts. 
This paper is structured as follows. The next section (Section 2) will present a review of existing user acceptance models. The following section (Section 3) deals with the research data and methods and discusses the ways in which the survey questionnaires were distributed and completed responses were gathered from the specific geographical locations of selected cities in India. Section 4 presents an overview of the Indian context and a specific egovernment system (i.e. the OPCRS). Section 5 presents empirical comparisons of the competing technology adoption models using the data gathered for the OPCRS. Section 6 presents the proposed research model and developed hypotheses to support the interrelationships among the constructs. Section 7 presents the factor loadings evaluated for all similar constructs of the UTAUT and selects the most appropriate items to form the constructs for the proposed model. Section 8 presents the results, including the demographic profile of the respondents, descriptive statistics, reliability analysis, the measurement model, and the structural model for the proposed model, including its model fit summary and the path coefficients for the hypothesized relationships. Section 9 provides discussions of the results presented in the previous section, along with limitations, future research directions, and implications for theory and practice. Finally, Section 10 presents the conclusion of the research.

\section{Review of Existing User Acceptance Models}

IS research has long studied how and why individuals adopt new information technologies. Within this wide area of investigation, there have been a number of streams of research (Venkatesh et al., 2003). One stream of research focuses on individual acceptance of technology by using intention or usage as a dependent variable (Compeau \& Higgins, 1995a; Davis et al., 1989), whereas other streams have looked at satisfaction or net benefits to measure the success of an IS (DeLone \& McLean, 1992, 2003), including at the enterprise 
level (Leonard-Barton \& Deschamps, 1988), or to measure task-technology fit (Goodhue, 1995; Goodhue \& Thompson, 1995). While each of these streams makes a significant contribution to the literature on users' acceptance of IT, the theoretical models to be included in the current review employ intention and/or usage as the key dependent variable(s) (Venkatesh et al., 2003). Table 1 describes the constructs relating to nine models of IT adoption and outlines the corresponding models to which these constructs are associated. In total, 29 different constructs are identified.

Table 1

Theories, Models, and Constructs of Individual Acceptance

\begin{tabular}{|c|c|c|}
\hline Model/Theory & Core Constructs & Source(s) \\
\hline \multirow{2}{*}{ TRA } & Attitude & \multirow{2}{*}{ Fishbein and Ajzen (1975) } \\
\hline & Subjective Norm & \\
\hline \multirow{2}{*}{ TAM } & Perceived Usefulness & \multirow{2}{*}{ Davis (1989), Davis et al. (1989) } \\
\hline & Perceived Ease of Use & \\
\hline \multirow{3}{*}{ TPB } & Subjective Norm & \multirow{2}{*}{ Adapted from TRA } \\
\hline & Attitude & \\
\hline & Perceived Behavioral Control & Ajzen (1991) \\
\hline \multirow{9}{*}{ DTPB } & Attitude & Adapted from TRA/TAM \\
\hline & Subjective Norm & \multirow{2}{*}{ Adapted from TPB } \\
\hline & Perceived Behavioral Control & \\
\hline & Perceived Ease of Use & \multirow{2}{*}{ Adapted from TAM } \\
\hline & Perceived Usefulness & \\
\hline & Compatibility & \multirow{3}{*}{ Taylor and Todd (1995b) } \\
\hline & Resource Facilitating Conditions & \\
\hline & Technology Facilitating Conditions & \\
\hline & Self-Efficacy & $\begin{array}{l}\text { Taylor and Todd (1995b), Compeau and Higgins } \\
\text { (1995a), Compeau and Higgins (1995b) }\end{array}$ \\
\hline \multirow{5}{*}{ SCT } & Output Expectation - Personal & \multirow{5}{*}{ Compeau and Higgins (1995a) } \\
\hline & Output Expectation - Professional & \\
\hline & Self-Efficacy & \\
\hline & Affect & \\
\hline & Anxiety & \\
\hline \multirow{8}{*}{ IDT } & Relative Advantage & \multirow{7}{*}{ Moore and Benbasat (1991), Rogers (1995) } \\
\hline & Compatibility & \\
\hline & Image & \\
\hline & Trialability & \\
\hline & Visibility & \\
\hline & Ease of Use & \\
\hline & Result Demonstrability & \\
\hline & Voluntariness of Use & Moore and Benbasat (1991) \\
\hline \multirow{6}{*}{ TAM2 } & Image & $\begin{array}{l}\text { Venkatesh and Davis (2000), Moore and Benbasat } \\
\text { (1991), Rogers (1995) }\end{array}$ \\
\hline & Perceived Usefulness & \multirow{2}{*}{ Davis (1989), Davis et al. (1989) } \\
\hline & Perceived Ease of Use & \\
\hline & Job Relevance & Venkatesh and Davis (2000) \\
\hline & Result Demonstrability & $\begin{array}{l}\text { Moore and Benbasat (1991), Rogers (1995), } \\
\text { Venkatesh and Davis (2000) }\end{array}$ \\
\hline & Subjective Norm & Adapted from TRA/TPB \\
\hline
\end{tabular}




\begin{tabular}{|l|l|l|}
\hline \multirow{4}{*}{ DOI } & Relative Advantage & \multirow{2}{*}{ Moore and Benbasat (1991), Rogers (1995) } \\
\cline { 2 - 2 } & Compatibility & \multirow{2}{*}{ Rogers (1995) } \\
\cline { 2 - 2 } & Complexity & \\
\cline { 2 - 2 } & Trialability & \multirow{3}{*}{ Venkatesh et al. (2003) } \\
\hline \multirow{4}{*}{ UTAUT } & Performance Expectancy & \\
\cline { 2 - 2 } & Effort Expectancy & \\
\cline { 2 - 3 } & Social Influence & Facilitating Conditions \\
\cline { 2 - 3 } & &
\end{tabular}

(Legend: DOI: diffusion of innovation, DTPB: decomposed theory of planned behavior, IDT: innovation diffusion theory, ISSM: information systems success model, SCT: social cognitive theory, TAM: technology acceptance model, TAM2: extended technology acceptance model, TPB: theory of planned behavior, TRA: theory of reasoned action, UTAUT: unified theory of acceptance and use of technology)

Existing studies on e-government adoption have largely used theories and models of IS/IT adoption as illustrated in Table 1. This study aimed to examine the performance of each theory or model using the data gathered for the OPCRS, formulated a UMEGA, and tested its performance. The unified model was developed based on the most appropriate measures available to be picked up from the set of UTAUT measures provided by Venkatesh et al. (2003), which were originally developed and used in the organizational setup. A brief summary of these theories/models is provided below.

\subsection{Theory of Reasoned Action (TRA)}

Derived from social psychology, the TRA is one of the most fundamental and influential theories of human behavior. It has been widely used as a model for the prediction of behavioral intention and/or behavior (Ajzen \& Fishbein, 1980; Fishbein \& Ajzen, 1975). The theory posits that behavioral intention, which is an immediate antecedent to behavior, is a function of salient information or beliefs about the likelihood that performing a particular behavior will lead to a specific outcome. Fishbein and Ajzen (1975) divide the beliefs antecedent into two conceptually different sets: behavioral and normative. Behavioral beliefs are postulated to have an underlying influence on an individual's attitude toward performing a behavior, whereas normative beliefs affect the individual's subjective norm about performing a behavior. Attitude is defined as an individual's positive or negative feelings about performing a target behavior, whereas subjective norm is defined as an individual's 
perception that most people who are important to him or her think that he/she should or should not perform the behavior in question (Fishbein \& Ajzen, 1975). Therefore, information or salient beliefs affect intentions and subsequent behavior either through attitudes or through subjective norms.

\subsection{Technology Acceptance Model (TAM)}

Davis (1986) introduced the TAM as an adaptation of the TRA for modeling users' acceptance of ISs. The goal of this model is to provide an explanation of the determinants of computer acceptance across a broad range of end-user computing technologies by remaining both parsimonious and theoretically justified. The TAM posits that two specific beliefs, perceived usefulness and perceived ease of use, are of key significance for computer acceptance behaviors. Perceived usefulness is defined as the prospective user's subjective probability that using a particular information system will enhance his or her job performance within the organizational context. Perceived ease of use refers to the level to which the prospective user expects using the target system to be free of effort (Davis et al., 1989).

\subsection{Theory of Planned Behavior (TPB)}

The TPB is an extension of the TRA made necessary by the original model's limitations in dealing with behaviors over which people have incomplete volitional control (Ajzen, 1991). In fact, the TPB differs from the TRA in its addition of perceived behavioral control. Perceived behavioral control refers to people's perception of the ease or difficulty associated with performing a behavior of interest. According to the theory, perceived behavioral control, together with behavioral intention, can be used directly to predict behavioral achievement. The TPB has been successfully implemented in the understanding of individual 
acceptance and usage of many different technologies (Harrison et al., 1997; Mathieson, 1991; Taylor \& Todd, 1995b).

\subsection{Decomposed Theory of Planned Behavior (DTPB)}

The DTPB is an alternative version of the TPB model with decomposed belief structures. The attitudinal, normative, and control beliefs in this model are decomposed into multidimensional belief constructs. By decomposing beliefs, those relationships should become clearer and more readily understood. In addition, the decomposition can provide a stable set of beliefs, which can be implemented across a variety of settings. Finally, by focusing on specific beliefs, the model becomes more managerially significant, pointing to particular factors that may impact adoption and usage. The DTPB shares many of the same advantages associated with the TAM. It differs from the TAM in that it is more complex, as it introduces a large number of factors that may affect usage. Due to this, the DTPB should provide a more complete understanding of IT usage in comparison to more-parsimonious models, like the TAM (Taylor \& Todd, 1995a).

\subsection{Social Cognitive Theory (SCT)}

SCT is one of the most powerful theories of human behavior (Bandura, 1986). Compeau and Higgins (1995b) applied and extended SCT to computer utilization, while Compeau and Higgins (1995a) also implemented SCT to study performance. Compeau and Higgins' (1995b) model studied computer use, but the nature of the model and the underlying theory allow it to be extended to the acceptance and use of IT in general. The original model of Compeau and Higgins (1995b) used usage as a dependent variable. However, keeping with the expectation of predicting individual acceptance, we examined the predictive validity of 
the model from the perspective of intention to allow its fair comparison with other models (Venkatesh et al., 2003).

The major exogenous variables used in the model are outcome expectations - performance, outcome expectations - personal, self-efficacy, affect, and anxiety. Outcome expectations performance is the performance-related consequence of the behavior, which primarily deals with job-related performance, whereas outcome expectations - personal is the personal consequence of the behavior, which deals with individual esteem and sense of accomplishment (Compeau \& Higgins, 1995b). Self-efficacy is defined as the judgment on the individual's ability to use a technology (e.g. computers) to accomplish a particular job or task (Compeau \& Higgins, 1995a). Moreover, affect is an individual's liking for a particular behavior (e.g. computer use). Finally, anxiety is defined as evoking anxious or emotional reactions when it comes to performing a behavior (e.g. using a computer).

\subsection{Diffusion of Innovation (DOI) / Innovation Diffusion Theory (IDT)}

Grounded in sociology, Rogers' (1995) DOI has been used since the 1960s to study a number of innovations, varying from agricultural tools to organizational innovations (Tornatzky \& Klein, 1982). This is one of the most popular models used for IS/IT research to describe users' adoption of new technologies. Diffusion is defined as the process by which the innovation is communicated to members of society using certain channels (Rogers, 1995). As per the DOI, the rate of diffusion is influenced by relative advantage, complexity, compatibility, trialability, and observability. IDT, developed by Moore and Benbasat (1991), adapted the attributes of innovation presented in Rogers' work and improved on the set of variables that could be used to study an individual's technology acceptance.

In addition to the five constructs prescribed by Rogers, they included constructs such as ease of use, result demonstrability, image, visibility, and voluntariness of use. Moore and 
Benbasat's (1991) study discussed the advancement of the instrument designed to assess users' insights on adopting IT innovations. Moreover, considerable amounts of IT acceptance and adoption research has been performed on the outcome of Rogers' work (Brancheau \& Wetherbe, 1990; Cooper \& Zmud, 1990; Huff \& Munro, 1985; Kwon \& Zmud, 1987). The original models of IDT (Moore \& Benbasat, 1991) and DOI (Rogers, 1983) supported initial adoption as a dependent variable. However, keeping with the expectation of predicting individual acceptance, we examined the predictive validity of the model from the perspective of intention to allow its fair comparison with other models.

\subsection{Extended Technology Acceptance Model (TAM2)}

Using the TAM as the starting point, the TAM2 incorporates additional theoretical constructs spanning social influence processes (subjective norm, voluntariness, and image) and cognitive instrumental processes (job relevance, output quality, result demonstrability, and perceived ease of use). Both these process types are found to significantly influence user acceptance. The TAM2 extends the TAM by showing that subjective norm exerts a significant direct influence on usage intentions over and above perceived usefulness and perceived ease of use for mandatory (but not voluntary) systems (Venkatesh \& Davis, 2000). This is one of the most widely used models in technology adoption research.

\subsection{Unified Theory of Acceptance and Use of Technology (UTAUT)}

Venkatesh et al. (2003) developed a unified model, called the unified theory of acceptance and use of technology (UTAUT), with four core determinants (i.e. performance expectancy, effort expectancy, social influence, and facilitating conditions) of intention and usage and up to four moderators (i.e. age, gender, experience, and voluntariness of use) of key relationships. The theory was developed through the review and integration of eight dominant theories and models (Venkatesh et al., 2003). Since its inception, the UTAUT has been 
extensively used in explaining a technology's acceptance by individuals. Due to the lack of variation in the moderator for the adoption and use context, we examined the validity of the model without using moderators in it. The similarity of the unified constructs used in the UTAUT model along with the other constructs and their definitions are provided later, alongside an explanation of the hypotheses developed for the proposed research model.

All these nine models of technology adoption have been used to examine the adoption of egovernment systems across different literature. However, these models in their original forms do not consider any e-government-specific constructs, such as trust, risk, security, or privacy, as discussed earlier. Moreover, as a number of alternative technology adoption models (see Table 1) are available, researchers are confronted with the option to pick and choose a favored model with some additional constructs and largely ignore the contributions from other alternative models (Venkatesh et al., 2003). In addition, only a few studies (e.g. Carter \& Schaupp, 2009; Schaupp et al., 2010; Yeow \& Loo, 2009) have empirically validated the UTAUT model in the e-government area.

Although these studies have used e-government-specific constructs, such as trust and risk (e.g. Carter \& Schaupp, 2009; Schaupp et al., 2010), alongside the basic UTAUT, the model has not performed at the expected level. This clearly indicates that there is a need for an egovernment-specific unified model to analyze its adoption. As a result, this study endeavored to formulate and test the UMEGA to fill this research gap.

\section{Research Data and Methods}

The sample of the study consisted of a wide spectrum of respondents from different cities of India, including Delhi (North India); Pune and Mumbai (West India); Bangalore (South India); and Patna, Siliguri, and Gangtok (East India), covering different demographics in India. Therefore, the sampling frame for this research consisted of the four geographic 
regions of India. The final questionnaire consisted of total 66 questions, including ten about respondents' demographic characteristics and the remaining 56 questions related to seven constructs of the proposed research model. All the questions were multiple-type, closedended, or seven-point Likert-scale questions. Likert scales (1-7) with anchors ranging from strongly disagree to strongly agree were used for all non-demographic items. Appendix A lists all the items for the constructs used in the study.

We visited all the cities above to personally distribute the questionnaire. The organizations in these cities were selected based on the personal contacts of the researchers and their friends and colleagues. Some people at the top-level management of different organizations, such as higher education institutions, banks, and software development organizations, were contacted to get as many responses as possible. The researchers visited these organizations personally to meet the different respondents to understand their views about the e-government systems. At the time of interacting with the respondents, we came to know that although the majority of them were computer and Internet literate, they were new to the OPCRS. Therefore, we decided to gather data only from non-adopters of the system. To institute the sample frame of citizens, respondents from different backgrounds were included, such as students, publicsector employees, private-sector employees, unemployed individuals, and pensioners.

We also collected data from students who were about to finish their academic courses and move on to their professional careers; they would need to obtain PAN cards to file returns on their incomes when they joined any private- or public-sector organization. As the respondents were not very aware of the system, we demonstrated this system to them largely in groups and gave them a maximum of a couple of days to interact with the system on their own before answering the questions. As far as the sampling technique for the given sampling frame was concerned, we used a non-probabilistic sampling technique for collecting data. This was simply due to the fact that every individual from the given sampling frame was not 
guaranteed to be selected for gathering data. We rather targeted only those respondents who were aware of e-government systems but had never explored the OPCRS before. In other words, this research did not ensure that every individual in the sample frame was necessarily considered as part of the sample. There were two basic reasons for this.

Firstly, this was a voluntary survey where only interested respondents were invited to take part. Secondly, the survey was designed to consider the responses of only non-adopters of the e-government systems. Therefore, those respondents who were either not interested in taking part in the survey or not adopters of this system (though only a handful of respondents were of that category) were simply not considered as part of this exercise. Moreover, gathering a sample in this fashion can be considered convenience sampling because it gathers a portion of the population that is close at hand, readily obtainable, or suitable to the researchers to conduct the survey. Therefore, the sampling for this research can be categorized as convenient non-probabilistic sampling, as respondents from different backgrounds were selected as per the convenience of the researchers in the diverse geographical locations in the country. In addition, the basic reasons for selecting the seven cities were largely motivated by the researchers' acquaintances and the need to represent cities from the east, west, north, and south zones of the country.

A total of 1,000 questionnaires were distributed to respondents through one-to-one and group interactions. Some respondents filled in the questionnaires and handed them in on the spot, whereas others took the questionnaires back to their homes and returned them after the specified time. A total of 474 completed survey questionnaires were received from various cities in India. Further scrutiny of the questionnaires revealed that 97 of them were either partially completed or filled in a biased manner (i.e. only one option ticked throughout the questionnaire), so they were rejected from subsequent analysis. Hence, we were left with 377 
usable responses, which formed the basis for the empirical analysis of the data. The overall response rate was found to be $47.4 \%$, with $37.7 \%$ valid questionnaires.

\section{The Indian Context and the OPCRS}

India is the largest democracy in the world. Prime Minister Modi believes that the success of democracy cannot be imagined without the participation of citizens (MyGov, 2014). Egovernment is referred to as e-governance in India; as e-governance can have a different meaning, we prefer to use the term e-government. The India government has given priority to projects with the potential to be scaled up (Kumar \& Misra, 2007). The National eGovernance Plan (NeGP) seeks to lay the foundation to enable the large-scale implementation of e-government. In this way, e-government in India has gradually advanced from the computerization of government departments to initiatives supporting citizen centricity, service orientation, and transparency. The NeGP aims at integrating initiatives across the country to create a shared vision (IGP, 2014).

In August 2014, the cabinet approved Digital India, which aims to transform the country into a digitally empowered society and knowledge economy. Digital India is transformational in nature and should ensure that government services are available to citizens electronically (PIB, 2014). Government services are currently provided using Common Service Centers (CSCs) across the country. There are different government levels (including central government, state governments, district administration, sub-districts or blocks, and village clusters) through which the services are provided to citizens. CSCs are front-end service delivery points at the village level for the delivery of government-initiated services to users, where most service delivery takes place. As of $31^{\text {st }}$ August 2013, about 127,000 CSCs were operational and were delivering services to people (INDG, 2014). 
The OPCRS is an e-government system for obtaining a PAN (Permanent Account Number) card in India. PAN is a ten-digit alphanumeric code, issued in the form of a laminated card by the Income Tax Department in India. It is mandatory to quote the PAN in all correspondence with the income tax authority and for any payments to the Income Tax Department in India. All existing taxpayers or persons who are required to furnish a return of income, even on behalf of others, must obtain a PAN. Although possessing a PAN is mandatory for all individuals who file an income tax return, the OPCRS is a voluntary e-government system for obtaining a PAN card. The PAN card is compulsory and required by authorities while doing financial transactions with them. For example, a photocopy of a PAN is required while applying for a new bank account; a PAN must also be quoted while applying for a debit or credit card, when paying into or opening a fixed deposit account, and when making a cash deposit exceeding 50,000 Indian rupees (RS) (about US\$750 in 2016). It must also be quoted when purchasing or selling a vehicle, buying/selling property, and when purchasing highvalue jewelry. Moreover, the government should receive the PAN details of each applicant with a normal phone or cellular connection to keep tabs on terrorism, extortion charges, and similar criminal activity, as mandated for all telecom companies. In addition, PAN card details are required in security investments and for trading on the stock market.

This system was implemented with the goal of easing an individual's burden of going through the cumbersome process of obtaining a PAN card through the tiring and timeconsuming offline process. As per recent statistics, about 50 million people in India pay direct tax on their incomes (for the year 2014/15), and this figure looks set to increase (Srivastava, 2016). The online system provides users with different facilities, including obtaining a new PAN for Indian citizens, reprinting a PAN card, obtaining a new PAN for foreign citizens, transactions status enquiry, changes or corrections in PAN details, and tracking a PAN application. As per Reserve Bank of India guidelines, personal identification 
numbers (PINs) are required when executing online transactions. Therefore, users need to make sure that they obtain PINs from their banks before making payments for PAN applications using debit and credit cards or Internet banking.

\section{Empirical Comparison of Nine Models of Technology Adoption}

Table 2 illustrates nine different theories/models of IS/IT adoption, which have been validated using the data collected for the OPCRS. The analysis of the models indicated that the TRA was a relatively better-performing model in comparison with the other models in terms of the significance of the relationships that attitude and subjective norm had with behavioral intention (each at $\mathrm{p}<0.001)$. It had the highest variance $(67 \%)$ among all the models in explaining behavioral intention, and reasonably acceptable fit indices (comparative fit index $(\mathrm{CFI})=0.915$, goodness-of-fit index $(\mathrm{GFI})=0.906$, adjusted GFI $(\mathrm{AGFI})=0.831)$ were obtained for the model. However, the chi-square by degree of freedom $\left(\chi^{2} / \mathrm{DF}=8.138\right)$ and the root mean square error of approximation (RMSEA) (0.138) values were way beyond the recommended levels (i.e. less than 0.06, as recommended by Hu \& Bentler (1999)).

Table 2

Comparison of Prior Technology Adoption Models

\begin{tabular}{|c|c|c|c|c|c|c|c|c|c|}
\hline $\begin{array}{l}\text { Model/ } \\
\text { Theory }\end{array}$ & IV & DV & PC & $\begin{array}{c}\text { Adjusted } \\
\mathbf{R}^{2} \\
\end{array}$ & $\begin{array}{c}\chi^{2} / \mathrm{DF} \\
(\mathbf{p})\end{array}$ & CFI & GFI & AGFI & RMSEA \\
\hline \multirow{2}{*}{ TRA } & AT & $\mathrm{BI}$ & $0.80 * * *$ & \multirow{2}{*}{$\mathrm{BI}=0.67$} & 8.138 & \multirow{2}{*}{0.915} & \multirow{2}{*}{0.906} & \multirow{2}{*}{0.831} & \multirow{2}{*}{0.138} \\
\hline & SN & $\mathrm{BI}$ & $0.18 * * *$ & & $(0.000)$ & & & & \\
\hline \multirow{3}{*}{ TAM } & PEOU & $\mathrm{BI}$ & $0.55 * * *$ & \multirow{2}{*}{$\mathrm{BI}=0.41$} & \multirow{3}{*}{$\begin{array}{c}7.374 \\
(0.000)\end{array}$} & \multirow{3}{*}{0.861} & \multirow{3}{*}{0.783} & \multirow{3}{*}{0.701} & \multirow{3}{*}{0.130} \\
\hline & $\mathrm{PU}$ & BI & $0.74 * * *$ & & & & & & \\
\hline & PEOU & $\mathrm{PU}$ & $0.12 \mathrm{~ns}$ & $\mathrm{PU}=0.55$ & & & & & \\
\hline \multirow{5}{*}{ SCT } & OEPR & $\mathrm{BI}$ & $0.12 *$ & \multirow{5}{*}{$\mathrm{BI}=0.42$} & \multirow{5}{*}{$\begin{array}{c}8.338 \\
(0.000)\end{array}$} & \multirow{5}{*}{0.730} & \multirow{5}{*}{0.693} & \multirow{5}{*}{0.615} & \multirow{5}{*}{0.140} \\
\hline & OEPL & $\mathrm{BI}$ & $-0.06 \mathrm{~ns}$ & & & & & & \\
\hline & SE & $\mathrm{BI}$ & $0.20 * * *$ & & & & & & \\
\hline & AFT & $\mathrm{BI}$ & $0.59 * * *$ & & & & & & \\
\hline & ANX & $\mathrm{BI}$ & $-0.09 \mathrm{~ns}$ & & & & & & \\
\hline \multirow{3}{*}{ TPB } & $\mathrm{AT}$ & $\mathrm{BI}$ & $0.76 * * *$ & \multirow{3}{*}{$\mathrm{BI}=0.65$} & \multirow{3}{*}{$\begin{array}{c}6.609 \\
(0.000)\end{array}$} & \multirow{3}{*}{0.878} & \multirow{3}{*}{0.846} & \multirow{3}{*}{0.782} & \multirow{3}{*}{0.122} \\
\hline & $\mathrm{SN}$ & $\mathrm{BI}$ & $0.12 *$ & & & & & & \\
\hline & PBC & $\mathrm{BI}$ & $0.25 * * *$ & & & & & & \\
\hline \multirow{3}{*}{ DTPB } & PEOU & AT & $0.51 * * *$ & \multirow{3}{*}{$\mathrm{AT}=0.30$} & \multirow{3}{*}{$\begin{array}{c}5.901 \\
(0.000)\end{array}$} & \multirow{3}{*}{0.742} & \multirow{3}{*}{0.628} & \multirow{3}{*}{0.574} & \multirow{3}{*}{0.114} \\
\hline & COMP & AT & $0.17 *$ & & & & & & \\
\hline & PU & $\mathrm{AT}$ & $0.10 \mathrm{~ns}$ & & & & & & \\
\hline
\end{tabular}




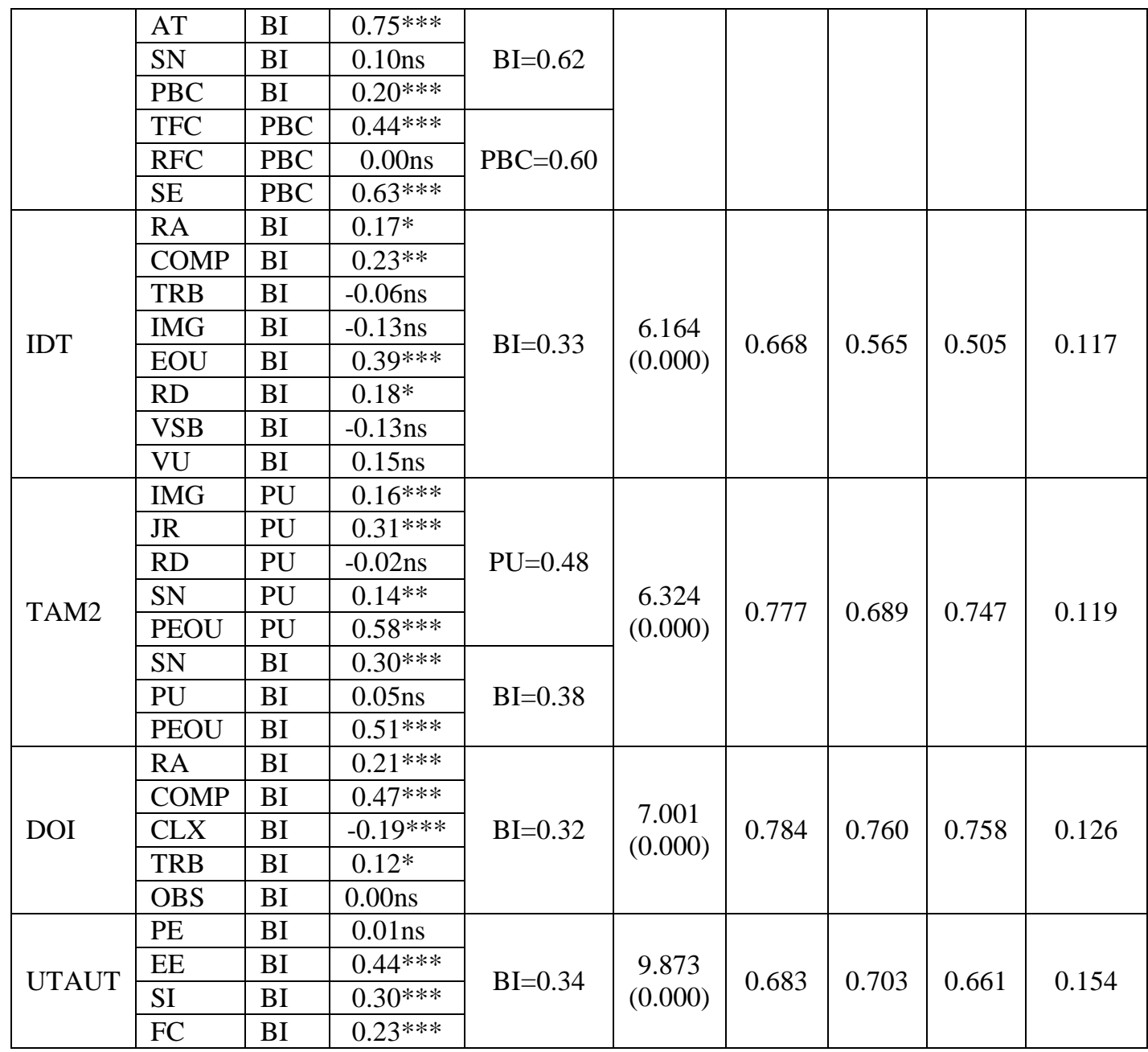

(Note: $\chi^{2}$ : chi-square; AFT: affect; AGFI: adjusted goodness-of-fit index; ANX: anxiety; AT: attitude; BI: behavioral intention; CFI: comparative fit index; CLX: complexity; COMP: compatibility; DF: degree of freedom; DV: dependent variable; EE: effort expectancy; EOU: ease of use; FC: facilitating conditions; GFI: goodness-of-fit index; IV: independent variable; IMG: image; JR: job relevance; ns: non-significant; OBS: observability; OEPL: output expectations - professional; OEPR: output expectations - personal; p: significance of chi-square by degree of freedom; PBC: perceived behavioral control; PC: path coefficient; PE: performance expectancy; PEOU: perceived ease of use; PU: perceived usefulness; RA: relative advantage; RD: result demonstrability; RFC: resource facilitating conditions; RMSEA: root mean square error of approximation; SE: self-efficacy; SI: social influence; SN: subjective norm; TFC: technology facilitating condition; TRB: trialability; VSB: visibility; VU: voluntariness to use)

Therefore, the model was not assumed to be absolutely reasonable as far as its overall performance is concerned. The TAM did not perform in accordance with its prior eminence, and the variance (41\%) explained by the model in behavioral intention and its fit indices $(\mathrm{CFI}=0.861, \mathrm{GFI}=0.783, \mathrm{AGFI}=0.701)$ were poorer than those of the TRA, which was less feasible in fulfilling the recommended criteria. Moreover, the chi-square by degree of freedom (7.374) and RMSEA (0.130) values were found to be close to those shown by the 
TRA and hence were unacceptable. However, the empirical test of the TRA indicated that attitude played an extremely vital role in determining behavioral intention. The strong and significant relationship between attitude and behavioral intention $(\gamma=0.80, \mathrm{p}<0.001)$ was possibly the reason why the variance explained by the TRA in behavioral intention was relatively high.

The strong relationship between attitude and behavioral intention and the relatively better performance of the model were also supported by the TPB and the DTPB. These models explained the second and third highest variance on behavioral intention respectively after the TRA. However, neither of these models seemed to reasonably fit the data provided, as the majority of their critical fit indices, such as $\chi^{2} / \mathrm{DF}$ (6.609 for TPB, 5.901 for DTPB), CFI (0.878 for TPB, 0.742 for DTPB), GFI (0.846 for TPB, 0.628 for DTPB), and RMSEA (0.122 for TPB, 0.114 for DTPB), did not perform as per their recommended levels.

Moreover, the other models, such as SCT, IDT, and the TAM2, underperformed in terms of the significance of one or more variables, the majority of fit indices, and comparably low variance on behavioral intention (see Table 2). For example, the fit indices (CFI=0.730, $\mathrm{GFI}=0.693$, AGFI=0.615) for SCT were very poor and much below the expected levels. In addition, the chi-square by degree of freedom (8.338) and RMSEA (0.140) values were also not found to represent the expected levels. Similar trends were also found for IDT $\left(\mathrm{CFI}=0.668, \quad \mathrm{GFI}=0.565, \quad \mathrm{AGFI}=0.505, \chi^{2} / \mathrm{DF}=7.001, \quad \mathrm{RMSEA}=0.117\right)$ and the TAM2 $\left(\mathrm{CFI}=0.777, \mathrm{GFI}=0.689, \mathrm{AGFI}=0.747, \chi^{2} / \mathrm{DF}=6.324, \mathrm{RMSEA}=0.119\right)$ models, where none of the indices' values were found to meet the recommended levels. Moreover, the variance explained by the models (33\% for IDT, $38 \%$ for the TAM2) in behavioral intention was also low, despite the higher number of variables determining behavioral intention in the context of these models. 
Further, the structural model testing for these two models indicated that two or more path coefficients for the relationships were found to be non-significant. For example, the relationships of trialability, image, visibility, and voluntariness to use with behavioral intention in IDT and those of result demonstrability and perceived usefulness with behavioral intention in the TAM2 were found to be non-significant. Hence, these models were not found to perform at the expected levels both as measurement models and in structural model testing. Even if the relationships of the DOI model were all significant, its fit indices $\left(\chi^{2} / \mathrm{DF}=7.001\right.$, $\mathrm{CFI}=0.784, \mathrm{GFI}=0.760, \mathrm{AGFI}=0.758)$ and the variance on behavioral intention $(32 \%)$ were considerably low; hence, the model did not truly represent the expected variance on the dependent variable using the data gathered for its analysis.

The UTAUT, which has been considered a recommended model in most of its implementations, was found to have all significant relationships, except the relationship between performance expectancy and behavioral intention; however, its fit indices $\left(\chi^{2} / \mathrm{DF}=9.873, \quad \mathrm{CFI}=0.683, \quad \mathrm{GFI}=0.703, \quad \mathrm{AGFI}=0.661, \quad \mathrm{RMSEA}=0.154\right) \quad$ significantly underperformed and possibly demonstrated the worst performance among all the models of IS/IT adoption. The model also explained low variance (0.34) in behavioral intention. The possible explanation for the deteriorating performance of the model was that the measures of the constructs affect its performance across different contexts. In other words, the original UTAUT model was found to perform best when it was implemented for technology acceptance in the private-sector organizational context. Therefore, it is not necessarily the case that the model with the same measures for its constructs will perform equally well in the e-government context. The e-government context differs from e-commerce primarily in three aspects: access, structure, and accountability (Carter \& Belanger, 2005; Jorgensen \& Cable, 2002). In e-commerce, businesses are allowed to choose their consumers, whereas in egovernment, government agencies are responsible for providing access to the overall eligible 
population, incorporating individuals from the lower-income group and accommodating for disabilities. However, the digital divide makes the accessibility of e-government services challenging at the various levels of society. Moreover, the structure of businesses is distinct from the structure of government agencies. Decision-making authorities are less centralized in government than in private-sector businesses. The decentralization of authority impedes the promptness and instantaneousness of the development and implementation of new egovernment services. The third distinction is in terms of accountability, which is very clearly defined in the private sector but remains relatively vague in the context of government agencies (Carter \& Belanger, 2005).

The above analyses of the alternative models of IS/IT adoption in the context of egovernment systems indicate that none of the models were appropriate to be considered to represent e-government systems adoption. Table 2 shows that these models underperformed, as fit indices, path coefficients, and other aspects did not perform as per the recommended levels. Hence, the lack of an appropriate theory gives rise to a further motivation toward formulating a unified model in this area of research (similar to the UTAUT to represent the IS/IT adoption perspective), which could preferably represent the e-government-specific context.

\section{Proposed Research Model and Hypothesis Development}

Table 2 presents the different relationships between the constructs in the existing models of IS/IT adoption, based on the data gathered from non-adopters of the OPCRS. The analyses indicated that none of the models performed acceptably in terms of their performance, such as their fit indices and variance on behavioral intention. However, the results clearly indicated that the performance of the models in the form of the significance of relationships between constructs, their fit indices, and the variance explained by the models on behavioral 
intention was much stronger for those models (the TRA, the TPB, and the DTPB) that had attitude as an independent or mediating variable. In addition, attitude itself showed a strong and highly significant relationship with behavioral intention in each of these models (the TRA, the TPB, and the DTPB). The research also acknowledged that even though the constructs (performance expectancy, effort expectancy, social influence, and facilitating conditions) of the original UTAUT (Venkatesh et al., 2003) model consisted of the majority of the constructs used in earlier dominant technology adoption models (e.g. the TRA, the TAM, the TPB, etc.), the UTAUT itself did not perform at the expected level.

As mentioned above, the possible reason for the UTAUT model not performing well in egovernment adoption might have been largely derived from the fact that the context of IS/IT adoption research is different to that of e-government adoption. For example, there is no role of factors such as trust, risk, security, and privacy in the adoption of any IS or IT. Moreover, all the items used for the unified constructs (such as performance expectancy, effort expectancy, social influence, and facilitating conditions) for the UTAUT model may not necessarily fully represent the e-government context. Hence, there is a need to develop an egovernment-specific unified model.

The key reason for selecting the UTAUT as a proposed research model for this research was largely derived from the fact that UTAUT is a unified model that comprises eight theoretical models of IS/IT adoption (Venkatesh et al., 2003). We examined some additional theories/models, such as IDT, the TAM2, and the DTPB, which are extensions of prior theories/models, such as the TRA, the TAM, the TPB, and the DOI. Therefore, a unified model is a choice that in fact tacitly represents all other dominant models of IS/IT adoption. Moreover, the integrated constructs of the UTAUT model largely characterize the constructs that were used in prior models. This is the reason why we decided to consider the UTAUT as the proposed base research model. 
Deriving from the enhanced performance of the models through the inclusion of attitude and the lack of individual constructs in the UTAUT model, we recommend including attitude as an individual mediating variable in the proposed model. The role of attitude in explaining technology acceptance is widely acknowledged in prior literature (e.g. Bobbitt \& Dabholkar, 2001; Kim et al., 2009; Taylor \& Todd, 1995b; Yang \& Yoo, 2004). Further, the inclusion of attitude in models of IS/IT acceptance is consistent with the TRA (Ajzen \& Fishbein, 1980; Fishbein \& Ajzen, 1975), the TPB (Ajzen, 1991), and the DTPB (Taylor \& Todd, 1995b). The TAM can be considered a special case of the TRA, with only two beliefs comprising attitude. The TRA claims that attitude completely mediates the relationship between these types of beliefs and intention (Taylor \& Todd, 1995b). Further, the TAM postulates that the easier a technology is to use, and the more useful it is perceived to be, the more positive one's attitude and intention toward using the technology (Davis et al., 1989; Taylor \& Todd, 1995b). The attitude $\leftarrow \rightarrow$ behavioral intention relationship represented in the TAM implies that, all else being equal, individuals form intentions to perform behaviors toward which they have positive attitudes. This relationship is central to the TRA and related models presented by Triandis (1977) and Bagozzi (1981) (Davis et al., 1989).

Specifically, we position attitude as a mediating variable between performance expectancy and behavioral intention, between effort expectancy and behavioral intention, between social influence and behavioral intention, and between perceived risk and behavioral intention. This is because the extent to which the OPCRS is useful, consistent with performance expectations, and easy to use can influence the individual's attitude, leading to behavioral intention. Moreover, suggestions and recommendations by important others can also influence individuals' attitudes toward using a system. A number of empirical studies (e.g. Aboelmaged, 2010; Aggelidis \& Chatzoglou, 2009; Egea \& González, 2011; Kim et al., 2010) have advocated the use of attitude as a mediating variable, along with perceived 
usefulness and perceived ease of use, in the TAM. Davis et al. (1989) argued that the perceived usefulness and behavioral intention relationship is fundamentally based on the idea that, within organizational settings, people form intentions toward behaviors they believe will enhance their job performance, over and above whatever positive or negative feelings they may have toward the behavior. As the current context is primarily linked to individuals, the importance of including attitude as a mediating variable in the proposed model should be seen in the backdrop of Davis et al.'s (1989) argument, which further strengthens and justifies the presence of this variable.

Attitude has also been used as a mediating variable between performance expectancy and effort expectancy in several studies that used the UTAUT (e.g. Alshare \& Lane, 2011; Koh et al., 2010; Sumak et al., 2010). Moreover, other studies (e.g. Chiu et al., 2012; Park et al., 2007) have also shown empirical support for the relationship between social influence and attitude in the context of the technology adoption literature in general. Based on this strong theoretical foundation (i.e. Ajzen, 1991; Davis, 1989; Fishbein \& Ajzen, 1975; Taylor \& Todd, 1995b) and prior empirical research (e.g. Chen \& Lu, 2011; Cox, 2012; Zhang \& Gutierrez, 2007), we propose that attitude instigates behavioral intention.

We also recommend including the relationship between facilitating conditions and behavioral intention in the proposed model. This is based on the theoretical foundations (Ajzen, 1991; Taylor \& Todd, 1995b) of its root constructs (such as perceived behavioral control and facilitating condition), followed by the empirical findings (e.g. Eckhardt et al., 2009; Foon \& Fah, 2011; Yeow \& Loo, 2009) that support the effect of facilitating conditions on behavioral intention. This research also argues that perceived risk could be used as an external variable of the proposed research model. Perceived risk might be considered a determinant of attitude, as the non-adopters of any e-government system would probably be more concerned about risk. 
The relevance of perceived risk as an external construct and its relationship with attitude indicates the relevance of risk as an important e-government-specific variable in the proposed unified model. The inclusion of perceived risk is also important in the current context because the e-government system considered in the current situation is transactional in nature, where risk plays a significant role toward an individual's decision of using and further adopting it. The inclusion of perceived risk in the e-government-specific proposed unified model is also in accordance with the call by Venkatesh et al. (2003) (the formulator of the UTAUT model) for a focus on identifying constructs that can add to the prediction of behavioral intention over and above what is already known and understood.

Although some prior studies (e.g. Abu-Shanab et al., 2010; Luo et al., 2010; McLeod et al., 2009; Sambasivan et al., 2010) have used risk as an endogenous variable, others (e.g. AbuShanab \& Pearson, 2009) have implemented it as an exogenous variable. When considering it as an endogenous variable, the studies on e-government adoption have shown that factors such as privacy, self-efficacy, and trust are well-known antecedents for this construct. However, to keep the proposed research model parsimonious and considering perceived risk as the major variable that impacts an individual's attitude toward using a particular research model, we implement it as the exogenous variable. The possible argument for not considering perceived risk as an endogenous variable in the current context is derived from the fact that the e-government system in question was relatively new and the respondents were nonadopters; therefore, it would have been difficult to predict and judge the impact of different socio-economic and demographic background factors and other variables (such as selfefficacy, security, privacy, perceived trust, etc.) on perceived risk in this case.

Therefore, under the proposed research model, we theorized that constructs such as performance expectancy, effort expectancy, social influence, and facilitating conditions would play a significant role as direct determinants of attitude and behavioral intention. 
Moreover, this research also considered perceived risk as an external variable to determine users' attitude, which would in turn influence behavioral intention. We argue that the moderators specified in the UTAUT were not applicable in the current research context, and that is why no moderators were included in the proposed model. One potential reason was that we were primarily interested in clarifying the direct relationships of exogenous constructs with attitude and behavioral intention, as other dominant models of technology adoption do with behavioral intention and use behavior, except for the UTAUT, which uses moderators. In other words, our intention was to provide a more simplified and moderatorless unified model that could test for direct relationships between the constructs. While devising the UTAUT2, Venkatesh et al. (2012) also noted that most studies employed only a subset of the model and that moderators were typically dropped.

The other reason for dropping moderators from the proposed model was primarily to present a parsimonious model that could be tested for any e-government situation, rather than depending too much on any specific context (such as age, gender, education, income, etc.), as models like the UTAUT (Venkatesh et al., 2003) and the UTAUT2 (Venkatesh et al., 2012) do. Moreover, even the UTAUT as a basic model can be compared with other models, where its theoretical consideration may preclude the use of moderators in the beginning. Such evaluation of the UTAUT allows us to understand its performance when the data related to all different moderating variables is combined. Figure 1 presents the proposed research model with appropriate hypotheses. 


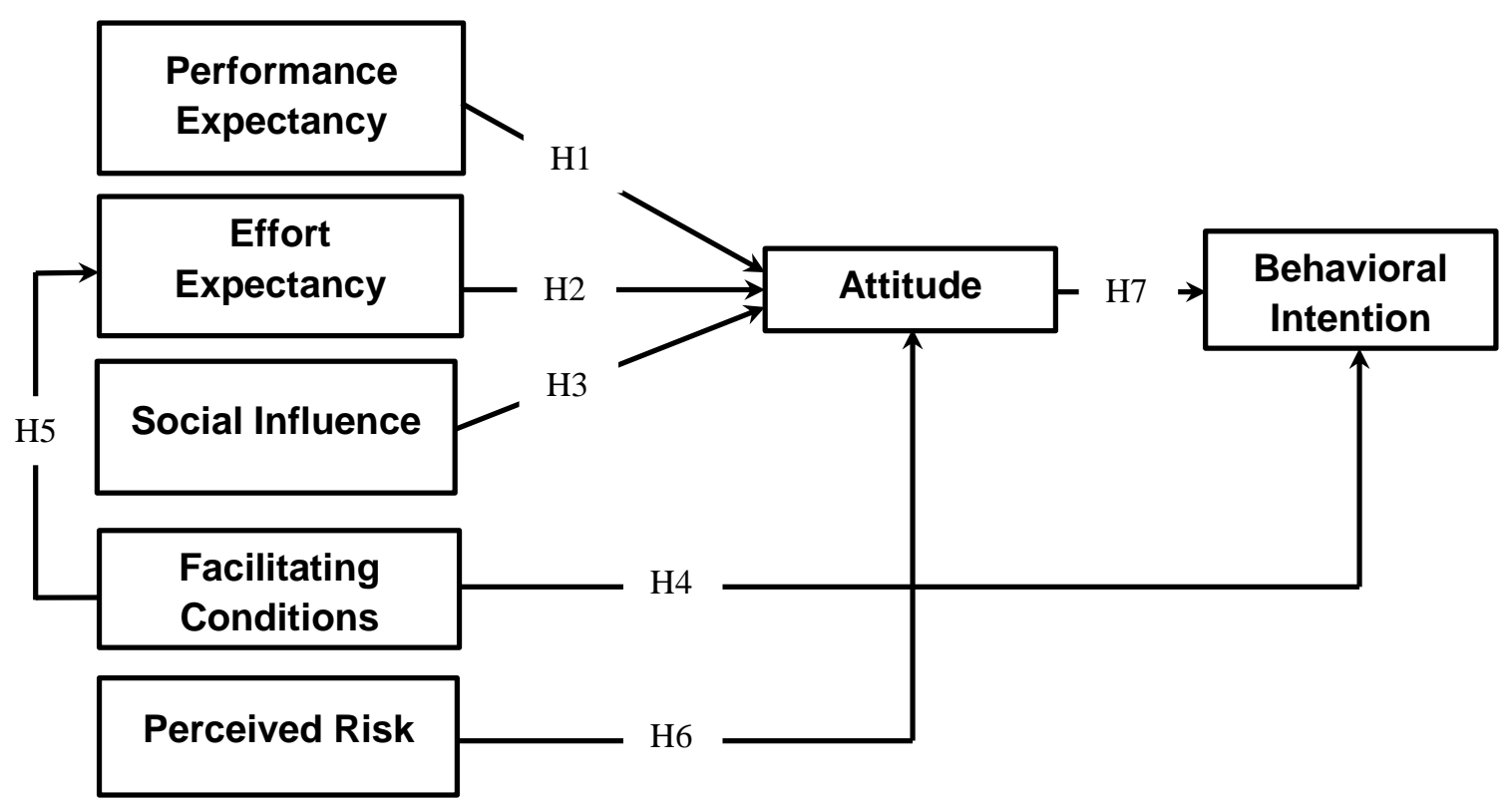

Fig. 1. Proposed UMEGA (adapted from Venkatesh et al., 2003; Rana et al. 2016; 2015a)

\subsection{Performance Expectancy}

Performance expectancy is defined as the degree to which a person believes that using the system will assist him or her in accomplishing improvements in job performance. The variables of the extant technology adoption models discussed in this research, including perceived usefulness (from the TAM and the TAM2), relative advantage (from the DOI and IDT), and outcome expectations (from SCT), are similar in nature to performance expectancy (Venkatesh et al., 2003). These constructs have been observed as similar to each other in some previous literature. For example, usefulness and relative advantage (Davis et al., 1989; Moore \& Benbasat, 1991; Plouffe et al., 2001) and usefulness and outcome expectations (Compeau \& Higgins, 1995a; Davis et al., 1989) have been regarded as similar constructs across various studies. The theoretical underpinnings of the TAM by Davis et al. (1989) and the DTPB by Taylor and Todd (1995b) indicate that perceived usefulness significantly determines an individual's attitude in the context of IS/IT adoption. As perceived usefulness is measured as one of the root constructs of performance expectancy in the UTAUT 
framework, it seemed reasonable to argue that performance expectancy would have a significant impact on an individual's attitude toward adopting the OPCRS.

Similarly, relative advantage is also considered as one of the root constructs of performance expectancy and has been found to be a significant determinant that impacts an individual's attitude toward adopting an e-government system. The positive and significant impacts of perceived usefulness on attitude have been examined in a number of studies (e.g. Hung et al., 2006, 2009, 2013; Lin et al., 2011; Lu et al., 2010) on e-government adoption. After the evolution and development of the UTAUT in 2003, a reasonable number of studies (e.g. Koh et al., 2010; Park et al., 2007; Pynoo et al., 2011) have examined the influence of performance expectancy on attitude. Their findings indicated that performance expectancy is a positive and significant determinant of an individual's attitude toward adopting or using the corresponding IS/IT systems. Considering the above discussions, the following hypothesis was formulated:

H1: Performance expectancy has a positive and significant influence on attitude toward using the OPCRS.

\subsection{Effort Expectancy}

Effort expectancy is defined as the level of simplicity associated with the use of a system (Davis et al., 1989). The three variables perceived ease of use (from the TAM and the TAM2), complexity (from the DOI and IDT), and ease of use (from IDT) summarize the concept of effort expectancy (Venkatesh et al., 2003). Similarities among these variables have been found in prior studies (Davis et al., 1989; Moore \& Benbasat, 1991; Plouffe et al., 2001; Thompson et al., 1991). Similar to perceived usefulness and entrenched in the theoretical underpinning of the TAM by Davis et al. (1989) and the DTPB by Taylor and Todd (1995b), perceived ease of use is a significant predictor of attitude in the technology adoption 
research. A number of studies (e.g. Park et al., 2007; Pynoo et al., 2011) have provided significant empirical justification for this relationship.

A reasonable number of studies (e.g. Hung et al., 2006, 2009, 2013; Lin et al., 2011; Lu et al., 2010) on e-government systems adoption have found a positive and significant relationship of perceived ease of use with attitude. For example, Hung et al. (2006) found this positive and significant relationship for an online tax filing and payment system, Hung et al. (2009) established it for an electronic document management system, and Hung et al. (2013) justified this relationship for several different e-government systems, including governmentto-business (G2B) e-government services and mobile e-government services. Exploring the citizens' adoption of e-government services in Gambia, Lin et al. (2011) found that perceived ease of use had a significant impact on a user's attitude. Examining the determinants influencing taxpayers' online tax filing in Taiwan, Lu et al. (2010) found that the perceived ease of use of the tax filing system significantly influenced a taxpayer's attitude. Hence, the following hypothesis was formulated:

H2: Effort expectancy has a positive and significant impact on attitude toward using the OPCRS.

\subsection{Social Influence}

Social influence is defined as the degree to which a person perceives that important others believe that he or she should use a new system (Venkatesh et al., 2003). This variable is composed of other similar variables, including subjective norm (from the TRA, the TAM2, the TPB, and the DTPB), social factors (from the model of PC utilization), and image (from IDT) (Venkatesh et al., 2003). Studies on technology adoption (e.g. Chiu et al., 2012; Park et al., 2007; Pynoo et al., 2007; Sumak et al., 2010) have also supported the positive and significant influence of social influence on attitude. For example, analyzing the adoption of an Internet lottery in Taiwan, Chiu et al. (2012) found that social influence was a significant 
determinant of users' attitudes across different age groups and varied levels of Internet experience. The findings of the research indicated that lottery gaming and online betting are subject to social influence, which allows players to easily link with each other (Chiu et al., 2012).

Similarly, exploring the adoption of mobile technologies by Chinese consumers, Park et al. (2007) found that social influence positively influenced a consumer's attitude toward using mobile technology. We also believe that societal influence from people of close proximity, such as members of family, friends, and colleagues, often has positive and certain levels of impact on an individual's attitude toward making decisions to use an e-government system like the OPCRS. Deriving from the above discussions and empirical support for this relationship, we formulated the following hypothesis:

H3: Social influence has a positive and significant impact on attitude toward using the OPCRS.

\subsection{Facilitating Conditions}

Facilitating conditions are defined as the level to which a person believes that an organizational and technical infrastructure is available to support the use of a system (Venkatesh et al., 2003). It captures concepts from other root variables, including perceived behavioral control (from the TPB and the DTPB), facilitating conditions (from the model of PC utilization), and compatibility (from IDT). Including perceived behavioral control (a root construct of facilitating conditions) as a predictor of behavioral intention in the TRA model, Ajzen (1991) formulated a new model called the TPB and established that such inclusion led to substantial improvements of the model in terms of predicting an individual's intentions.

Taylor and Todd (1995b) found a theoretical overlap by modeling facilitating conditions as a key constituent of perceived behavioral control in the TPB/DTPB. The authors argued that 
for inexperienced users, perceived behavioral control had relatively less impact on intention. Venkatesh et al. (2003) argued that when constructs such as performance expectancy and effort expectancy are present to predict the intention, facilitating conditions become insignificant in predicting behavioral intention. In comparison to the UTAUT conceptualization, Venkatesh et al. (2012) added a direct relationship between facilitating conditions and behavioral intention in the UTAUT2, which was primarily developed to address a consumer's adoption of technology. Giving reference to the UTAUT, it was argued that facilitating conditions were hypothesized to influence technology use in the organizational environment, where facilitating conditions can serve as the proxy for actual behavioral control and can influence behavior directly (Ajzen, 1991).

However, the assistance offered by the IS/IT in the case of each individual can vary considerably across application vendors, technology generations, and devices used to run the application. In such cases, facilitating conditions work more like perceived behavioral control and influence behavioral intention as well (Venkatesh et al., 2012). Empirical evidence from a number of studies (e.g. Chiu et al., 2012; Lee \& Lin, 2008) on technology adoption by individuals has also supported the significant impact of facilitating conditions on behavioral intention.

Moreover, the relationship between facilitating conditions and behavioral intention in egovernment adoption research has been explored across a reasonable number of studies (e.g. Carter et al., 2012; Schaupp et al., 2010), and it was found that facilitating conditions had a significant impact on an individual's intention to use a system. For example, analyzing e-file utilization among US taxpayers, Carter et al. (2012) revealed that facilitating conditions were significant in explaining the intention to use e-files. Similarly, analyzing US taxpayers' intentions to adopt e-files, Schaupp et al. (2010) found that facilitating conditions had a 
significant impact on behavioral intention. Based on the above discussions, the following hypothesis was formulated:

H4: Facilitating conditions have a positive and significant impact on behavioral intention. A handful of studies (e.g. Alrawashdeh et al., 2012; Schaper \& Pervan, 2007; Urumsah et al., 2011) on IS/IT adoption have also supported the positive and significant impact of facilitating conditions on effort expectancy. For example, while examining the factors impacting the acceptance of a web-based training system among employees in Jordan, Alrawashdeh et al. (2012) found a newly detected significant relationship between facilitating conditions and effort expectancy. Similarly, exploring ICT acceptance and utilization by Australian occupational therapists, Schaper and Pervan (2007) found a positive and significant relationship between facilitating conditions and effort expectancy. In addition, investigating the factors influencing consumers to use the e-services of Indonesian airlines, Urumsah et al. (2011) found that a consumer's access to and use of the services were influenced by the good-quality technical infrastructures and support provided by the airlines. We also believe that facilitating conditions, such as providing initial training and necessary resources to users, might help them to easily understand and explore the system. Therefore, we hypothesized:

H5: Facilitating conditions have a positive and significant impact on effort expectancy.

\subsection{Perceived Risk}

Recent research advocates that an individual's perceptions concerning the risks linked with online transactions are a key restraint to electronic services adoption. Prior literature on perceived risk found that 80 percent of Internet users are concerned about making their personal identities known on the web (Rana et al., 2015b; Schaupp \& Carter, 2010). IT risks are related to the likelihood that a system is inadequately protected from different forms of 
damages (Straub \& Welke, 1998). A user's perceived risk is defined as the conviction that he or she will suffer a loss while seeking an outcome (Warkentin et al., 2002).

Perceived risk consists of behavioral and environmental insecurity. Behavioral insecurity exists because of the unfriendly nature of the Internet, whereas environmental insecurity occurs due to the capricious nature of Internet-based technology (Zhang \& Maruping, 2008). Gefen et al. (2003) noted that perceived risk is an individual subjective expectation of suffering loss in pursuit of a desired outcome. Empirical evidence has also shown that reduced perceived risk significantly influences adopters' attitudes (Hung et al., 2006; Susanto \& Goodwin, 2011). Analyzing a specific e-government system called myEPF in the Malaysian context, Sulaiman et al. (2012) found that perceived risk was negatively but significantly associated with users' attitudes. The theoretical models on e-commerce adoption (e.g. Lu et al., 2005; Teo \& Liu, 2007) have also found a negative and significant relationship between perceived risk and attitude. In the context of this research, we also believe that the perceived risk of users associated particularly with the transactional e-government system emphasized the risk involved in using it. Such risks are directly associated with the user's negative feeling about using the system specifically when they are comparatively new to the system's use. Therefore, it was hypothesized that:

H6: Perceived risk has a negative and significant impact on an individual's attitude toward using the OPCRS.

\subsection{Attitude}

The construct attitude has been used across various theories of IS/IT adoption research, including the TRA (Fishbein \& Ajzen, 1975), the TAM (Davis et al., 1989), the TPB (Ajzen, 1991), and the DTPB (Taylor \& Todd, 1995b), to measure its influence on behavioral intention to use a system. As per the TRA, a person's behavioral intention is jointly determined by the individual's attitude and subjective norm concerning the behavior in 
question (Fishbein \& Ajzen, 1975). Similar to the TRA, the TAM postulates that an individual's behavioral intention is determined by the individual's attitude toward using the system (Davis et al., 1989). Attitude toward behavior is defined as the level to which an individual has a positive or negative evaluation or appraisal of the behavior in question (Ajzen, 1991). Formulating the TPB model, Ajzen (1991) postulated that attitude toward behavior is generally found to precisely predict the individual's behavioral intention.

Studies based on the TPB model have also supported this assertion, presenting that attitude can significantly influence the intention to use a new IS/IT (Mathieson, 1991; Pavlou \& Fygenson, 2006; Taylor \& Todd, 1995b). In fact, similar to the TAM, Taylor and Todd (1995b) established attitude as a mediating variable, which leads to a higher overall intention to use a system. In the field of public administration and e-government, a number of studies (e.g. Hung et al., 2009, 2013; Lu et al., 2010) have supported the relationship between attitude and behavioral intention. For example, analyzing users' acceptance of mobile egovernment services in Taiwan, Hung et al. (2013) found attitude to be a critical factor for understanding and predicting mobile users' behavioral intentions. Realizing its importance in IS/IT adoption research in general and e-government adoption in particular, the following hypothesis was formulated:

H7: An individual's attitude toward using the system has a positive and significant relationship with intention.

\section{Selection of Most Appropriate Items}

Table 3 presents the items of the proposed research model and their corresponding factor loadings. While formulating the UTAUT, Venkatesh et al. (2003) adopted the approach where they selected the four highest loading items for each determinant from the 
measurement model. We adopted a similar approach, where the higher loading items from similar constructs constituting the variables were selected and used for the UMEGA.

While choosing the items, we ensured that we picked a minimum of three items for a construct in the proposed model either beyond the recommended level of factor loading (i.e. $\geq 0.40$ ) or some of the highly loading items that enhanced the performance of the proposed model (Field, 2005). For example, we selected four highly loading items, including two each from both subjective norm and social factors, to constitute the items for social influence. Further, realizing that some of the relatively lower loading items (e.g. SF2 and SF3) might adversely affect the performance of the proposed research model, it was decided to drop them from the selected set of items forming a construct. In addition, even though some of the items of effort expectancy, such as EOU4 and EU1EOU3, were relatively highly loading factors, their presence had an adverse impact on the performance of the model. Hence, only three highly loading items were selected in this case.

Table 3

Item Loadings Using AMOS $(\mathrm{N}=377)$

\begin{tabular}{|c|c|c|c|c|c|}
\hline Measure & Items & FL & Measure & Items & FL \\
\hline \multirow[b]{3}{*}{ 兵 } & OE1 & 0.67 & \multirow{3}{*}{$\underbrace{\widehat{\theta}}_{0}$} & SN1* & 0.83 \\
\hline & OE2 & 0.63 & & SN2* & 0.84 \\
\hline & OE3 & 0.67 & & SF1* & 0.60 \\
\hline \multirow{4}{*}{ 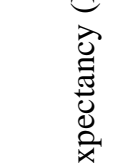 } & OE4 & 0.65 & \multirow{6}{*}{$\begin{array}{l}\stackrel{\mathscr{J}}{\leftrightarrows} \\
\Xi \\
. \frac{\pi}{0} \\
0 \\
\mathscr{\Omega}\end{array}$} & SF2 & 0.58 \\
\hline & OE5 & 0.50 & & SF3 & 0.59 \\
\hline & OE6 & 0.63 & & SF4* & 0.65 \\
\hline & OE7 & 0.60 & & IMG1 & 0.46 \\
\hline \multirow{7}{*}{ 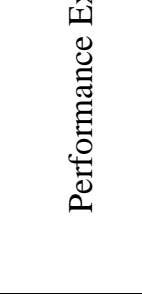 } & PU2 & 0.60 & & IMG2 & 0.43 \\
\hline & PU6* & 0.78 & & IMG3 & 0.43 \\
\hline & RA2 & 0.60 & \multirow{8}{*}{ 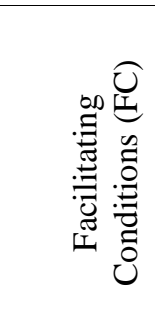 } & PBC1* & 0.77 \\
\hline & RA1, PU1* & 0.74 & & PBC2 & 0.57 \\
\hline & RA3, PU5* & 0.77 & & PBC3* & 0.78 \\
\hline & RA4, PU4* & 0.78 & & PBC4* & 0.81 \\
\hline & RA5, PU3 & 0.56 & & PBC5* & 0.77 \\
\hline \multirow{10}{*}{ 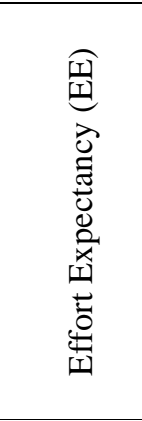 } & EOU4 & 0.79 & & FC1 & 0.66 \\
\hline & EOU5 & 0.74 & & FC2* & 0.70 \\
\hline & EU1, EOU3 & 0.79 & & FC3 & 0.51 \\
\hline & EU3, EOU6* & 0.86 & \multirow{7}{*}{ 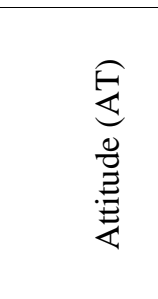 } & AT1* & 0.90 \\
\hline & EU4, EOU1* & 0.82 & & AT2* & 0.81 \\
\hline & EU2, EOU2* & 0.81 & & AT3* & 0.87 \\
\hline & CLX1 & 0.26 & & AT4 & 0.71 \\
\hline & CLX2 & 0.26 & & AFT1 & 0.72 \\
\hline & CLX3 & 0.24 & & AFT2 & 0.67 \\
\hline & CLX4 & 0.29 & & AFT3 & 0.71 \\
\hline
\end{tabular}




\begin{tabular}{|c|c|c|c|c|c|}
\hline \multirow{4}{*}{ 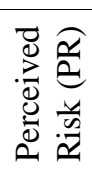 } & PR1* & 0.74 & & AFT4 & 0.45 \\
\hline & PR2* & $\mathbf{0 . 8 3}$ & \multirow{3}{*}{$\begin{array}{l}\text { Behavioral } \\
\text { Intention } \\
\text { (BI) }\end{array}$} & BI1* & 0.75 \\
\hline & PR3* & 0.83 & & BI2* & 0.78 \\
\hline & PR4* & 0.89 & & BI3* & $\overline{0.80}$ \\
\hline
\end{tabular}

The selected items (marked using '*' in Table 3) resulted in the highest and most appropriate loading factors. This included four items from performance expectancy (RA1PU1, RA3PU5, RA4PU4, and PU6), three items from effort expectancy (EU3EOU6, EU4EOU1, and EU2EOU2), four items from social influence (SN1, SN2, SF1, and SF4), and five from facilitating conditions (PBC1, $\mathrm{PBC} 3, \mathrm{PBC} 4, \mathrm{PBC} 5$, and $\mathrm{FC} 2)$. Moreover, three items each from the constructs attitude (AT1, AT2, and AT3) and behavioral intention (BI1, BI2, and $\mathrm{BI} 3$ ) and four from perceived risk (PR1, PR2, PR3, and PR4) were also found useful in contributing toward the proposed model development.

\section{Results}

\subsection{Respondents’ Demographic Profile}

The characteristics of the data gathered from the respondents from various geographical locations indicated that the majority of the population was from a relatively younger generation. For example, $75.6 \%$ of the respondents belonged to the age group 20-34 years (see Table 4). As far as the occupations of the respondents were concerned, $62.6 \%$ of the total sample were private- and public-sector employees; $27.1 \%$ represented students at undergraduate and postgraduate level. The education qualification level for close to $87.8 \%$ of the overall population was found to be undergraduate or above. The computer and Internet literacy and awareness of the respondents can be visualized as very high computer and Internet experience of approximately $96 \%$. The Internet use frequency of the respondents 
indicated that more than two-thirds $(69.2 \%)$ of the overall population always or very frequently used the Internet.

Table 4

Respondents' Demographic Profile

\begin{tabular}{|c|c|c|c|c|c|}
\hline Category & Count & $\%$ & Category & Count & $\%$ \\
\hline Age Group & - & - & & - & - \\
\hline 20-24 Years & 104 & 27.6 & College/University & 74 & 13.6 \\
\hline 25-29 Years & 126 & 33.4 & Common Service Center & 9 & 1.7 \\
\hline 30-34 Years & 55 & 14.6 & No Access & 8 & 1.5 \\
\hline 35-39 Years & 33 & 8.8 & Total & 377 & 100 \\
\hline 40-44 Years & 16 & 4.2 & Computer Experience (in Years) & & \\
\hline 45-49 Years & 15 & 4.0 & No Experience & 15 & 4.0 \\
\hline 50-54 Years & 14 & 3.7 & $1-3$ Years & 74 & 19.6 \\
\hline 55-59 Years & 7 & 1.9 & 4-6 Years & 105 & 27.9 \\
\hline$>=60$ Years & 7 & 1.9 & 7-9 Years & 88 & 23.3 \\
\hline Total & 377 & 100 & $>=10$ Years & 95 & 25.2 \\
\hline Gender & - & - & Total & 377 & 100 \\
\hline Male & 250 & 66.3 & Internet Access Location & - & - \\
\hline Female & 127 & 33.7 & Home & 229 & 42.6 \\
\hline Total & 377 & 100 & Office & 155 & 28.9 \\
\hline Educational Qualification & - & - & Internet Café & 64 & 11.9 \\
\hline Non-Matriculation & 1 & 0.3 & College/University & 70 & 13.0 \\
\hline Matriculation & 5 & 1.3 & Common Service Center & 9 & 1.7 \\
\hline $10+2 /$ Intermediate & 40 & 10.6 & No Access & 10 & 1.9 \\
\hline Graduate & 154 & 40.8 & Total & 377 & 100 \\
\hline Postgraduate & 153 & 40.6 & Internet Experience (in Years) & - & - \\
\hline Postgraduate Research & 24 & 6.4 & No Experience & 11 & 2.9 \\
\hline Total & 377 & 100 & $1-3$ Years & 116 & 30.8 \\
\hline Occupation & - & - & 4-6 Years & 116 & 30.8 \\
\hline Employee - Private Sector & 178 & 47.2 & 7-9 Years & 65 & 17.2 \\
\hline Student & 102 & 27.1 & $>=10$ Years & 69 & 18.3 \\
\hline Employee - Public Sector & 58 & 15.4 & Total & 377 & 100 \\
\hline Self-Employed & 20 & 5.3 & Internet Use Frequency & - & - \\
\hline Unemployed & 16 & 4.2 & Never & 9 & 2.4 \\
\hline Pensioner & 3 & 0.8 & Very Rarely & 13 & 3.4 \\
\hline Total & 377 & 100 & Rarely & 32 & 8.5 \\
\hline Computer Access Location & - & - & Occasionally & 62 & 16.4 \\
\hline Home & 242 & 44.6 & Very Frequently & 160 & 42.4 \\
\hline Office & 156 & 28.7 & Always & 101 & 26.8 \\
\hline Internet Café & 54 & 9.9 & Total & 377 & 100 \\
\hline
\end{tabular}




\subsection{Descriptive Statistics}

Table 5 presents the means and standard deviations for the selected items of each construct used for the proposed research model. The mean values of all constructs (except for perceived risk) were found to be either close to 5 or above it. This indicated that users responded favorably to the system at large. However, a relatively lower mean value of around 4 for the items for the construct perceived risk indicated that respondents did not respond positively to the items related to this construct. Relatively higher standard deviations (particularly close to 1.5 or higher) for every item of perceived risk (PR1, PR2, PR3, and PR4), social influence (SN1, SN2, SF1, and SF4), performance expectancy (RA1PU1 and RA4PU4), and behavioral intention (BI1 and BI3) indicated that responses relatively diverged across the corresponding mean values, which means that the respondents seemed to offer varying opinions about the questions asked of them.

Table 5

Means and Standard Deviations (SD) of Items (N=377)

\begin{tabular}{|c|c|c|c|c|c|}
\hline Construct & CA & ID & $\operatorname{Item}(\mathbf{s})$ & Mean & SD \\
\hline \multirow{4}{*}{ Performance Expectancy (PE) } & \multirow{4}{*}{0.829} & \multirow{4}{*}{10} & RA1, PU1 & 5.18 & 1.470 \\
\hline & & & RA3, PU5 & 5.37 & 1.374 \\
\hline & & & RA4, PU4 & 5.15 & 1.474 \\
\hline & & & PU6 & 5.34 & 1.318 \\
\hline \multirow{3}{*}{ Effort Expectancy (EE) } & \multirow{3}{*}{0.855} & \multirow{3}{*}{7} & EU3, EOU6 & 5.33 & 1.310 \\
\hline & & & EU4, EOU1 & 5.38 & 1.289 \\
\hline & & & EU2, EOU2 & 5.19 & 1.325 \\
\hline \multirow{4}{*}{ Social Influence (SI) } & \multirow{4}{*}{0.807} & \multirow{4}{*}{5} & SN1 & 4.93 & 1.500 \\
\hline & & & SN2 & 4.95 & 1.533 \\
\hline & & & SF1 & 4.94 & 1.506 \\
\hline & & & SF4 & 5.03 & 1.521 \\
\hline \multirow{5}{*}{ Facilitating Conditions (FC) } & \multirow{5}{*}{0.884} & \multirow{5}{*}{3} & PBC1 & 5.10 & 1.402 \\
\hline & & & PBC3 & 5.33 & 1.310 \\
\hline & & & PBC4 & 5.40 & 1.270 \\
\hline & & & PBC5 & 5.17 & 1.318 \\
\hline & & & $\mathrm{FC} 2$ & 5.11 & 1.453 \\
\hline \multirow{4}{*}{ Perceived Risk (PR) } & \multirow{4}{*}{0.899} & \multirow{4}{*}{0} & PR1 & 4.45 & 1.745 \\
\hline & & & PR2 & 4.15 & 1.842 \\
\hline & & & PR3 & 4.32 & 1.798 \\
\hline & & & PR4 & 4.25 & 1.852 \\
\hline \multirow{3}{*}{ Attitude (AT) } & \multirow{3}{*}{0.891} & \multirow{3}{*}{5} & AT1 & 5.59 & 1.320 \\
\hline & & & AT2 & 5.50 & 1.380 \\
\hline & & & AT3 & 5.63 & 1.315 \\
\hline \multirow{3}{*}{ Intention (BI) } & \multirow{3}{*}{0.847} & \multirow{3}{*}{0} & BI1 & 5.31 & 1.457 \\
\hline & & & $\mathrm{BI} 2$ & 5.29 & 1.419 \\
\hline & & & $\mathrm{BI} 3$ & 5.33 & 1.455 \\
\hline
\end{tabular}

(Legend: CA: Cronbach's alpha, ID: items dropped) 
Reliability analysis was implemented using Cronbach's alpha. It is used for evaluating the reliability of a scale, which provides an indication of the internal consistency of the items measuring the same construct (Hair et al., 1992; Zikmund, 1994). The Cronbach's alpha (see Table 5) for all the constructs was found to exceed the recommended minimum acceptable level of 0.70 (Hair et al., 1992; Nunnaly, 1978). In addition, Table 5 also presents the number of dropped items from the constructs to be considered for the proposed unified model for egovernment adoption. The highest ten items were dropped from performance expectancy, whereas no items were dropped from the behavioral intention and perceived risk constructs. The dropped items were largely those items that were repetitive in nature because they had been taken from similar constructs and from different theories. Dropping these items did not affect the actual performance of the model and provides unduplicated measurements for future researchers. Moreover, factor loadings for some of them were also found to be less than the threshold value of 0.50 (see Table 3 for the factor loading values of various items) (Fornell \& Larcker, 1981).

\subsection{Measurement Model}

The study tested the convergent and discriminant validity of the scales using confirmatory factor analysis as part of justifying the measurement model. Anderson and Gerbing (1988) recommended three ad hoc tests for convergent validity. Table 6 illustrates the standardized factor loadings, composite reliabilities, and average variance extracted for this purpose. Standardized factor loadings are representative of the level of association between scale items and a single latent variable. The loadings were found to be highly significant in all cases. Composite reliabilities (CRs), similar to the Cronbach's alpha values, were found to be well beyond the minimum limit of 0.70 (as recommended by Hair et al., 1992; Nunnaly, 1978) in 
each case. Average variance extracted (AVE) estimates are measures of the variation explained by the latent variable to random measurement error (Netemeyer et al., 1990). The AVE ranged from 0.722 to 0.864 for all constructs. These estimates were way beyond the recommended lower limit of 0.50 (Fornell \& Larcker, 1981). Hence, the convergent validity in all three tests related to the scales was supported.

Table 6

Results of the Confirmatory Factor Analysis (CFA)

\begin{tabular}{|l|c|c|c|}
\hline Measure & FL & CR & AVE \\
\hline Performance Expectancy (PE) & & 0.852 & 0.772 \\
\hline RA1PU1 & 0.74 & & \\
\hline RA3PU5 & 0.77 & & \\
\hline PU6 & 0.78 & & \\
\hline RA4PU4 & 0.78 & & \\
\hline Effort Expectancy (EE) & & 0.869 & 0.821 \\
\hline EU3EOU6 & 0.86 & & \\
\hline EU4EOU1 & 0.82 & & \\
\hline EU2EOU2 & 0.81 & & \\
\hline Social Influence (SI) & & 0.824 & 0.722 \\
\hline SN1 & 0.83 & & \\
\hline SN2 & 0.84 & & \\
\hline SF1 & 0.60 & & \\
\hline SF4 & 0.65 & & \\
\hline Facilitating Conditions (FC) & & 0.870 & 0.795 \\
\hline PBC1 & 0.77 & & \\
\hline PBC3 & 0.78 & & \\
\hline PBC4 & 0.81 & & \\
\hline PBC5 & 0.76 & & \\
\hline FC2 & 0.66 & & \\
\hline Perceived Risk (PR) & & 0.894 & 0.852 \\
\hline PR1 & 0.74 & & \\
\hline PR2 & 0.83 & & \\
\hline PR3 & 0.83 & & \\
\hline PR4 & 0.89 & & \\
\hline Attitude (AT) & & 0.895 & 0.864 \\
\hline AT1 & 0.90 & & \\
\hline AT2 & 0.81 & & \\
\hline AT3 & 0.87 & & \\
\hline Behavioral Intention (BI) & & 0.820 & 0.734 \\
\hline BI1 & 0.75 & & \\
\hline BI2 & 0.78 & & \\
\hline BI3 & 0.80 & & \\
\hline average varance & & \\
\hline
\end{tabular}

(Legend: AVE: average variance extracted, CR: composite reliability, FL: factor loading)

Discriminant validity was also measured using the test recommended by Anderson and Gerbing (1988). To pass this test, the factor correlation between a pair of latent variables should be less than the square root of the AVE (as shown along the diagonal of Table 7 in a 
bold font) of each variable, as shown in Table 7 through the factor correlation matrix. The evaluation of this validity indicated that the square root of the AVE for each variable was always greater than the correlation value for any pair of variables. For example, the correlation between attitude and behavioral intention was 0.732 , which was less than the square root of the AVE shown along the diagonal of both these variables $(0.930$ and 0.857 , respectively). Similarly, the correlation between performance expectancy and facilitating conditions was 0.802 , which was less than the square root of the AVE for both these variables (0.879 and 0.891 , respectively). In other words, a variable is considered different from other variables if the square root of the AVE for it is greater than its correlations with other latent variables (Barclay \& Smith, 1997), which was satisfied for every variable of the proposed research model of the current study.

Table 7

Factor Correlation Matrix

\begin{tabular}{|c|c|c|c|c|c|c|c|}
\hline Variable & PE & EE & SI & FC & PR & AT & BI \\
\hline PE & $\mathbf{0 . 8 7 9}$ & & & & & & \\
\hline EE & $0.754^{* *}$ & $\mathbf{0 . 9 0 6}$ & & & & & \\
\hline SI & $0.515^{* *}$ & $0.436^{* *}$ & $\mathbf{0 . 8 5 0}$ & & & & \\
\hline FC & $0.802^{* *}$ & $0.740^{* *}$ & $0.518^{* *}$ & $\mathbf{0 . 8 9 1}$ & & & \\
\hline PR & $0.114^{*}$ & $0.098 \mathrm{~ns}$ & $0.327^{* *}$ & $0.216^{* *}$ & $\mathbf{0 . 9 2 3}$ & & \\
\hline AT & $0.570^{* *}$ & $0.551^{*}$ & $0.416^{* *}$ & $0.524^{* *}$ & $-0.035 \mathrm{~ns}$ & $\mathbf{0 . 9 3 0}$ & \\
\hline BI & $0.540^{* *}$ & $0.556^{* *}$ & $0.422^{* *}$ & $0.558^{* *}$ & $0.008 \mathrm{~ns}$ & $0.732^{* *}$ & $\mathbf{0 . 8 5 7}$ \\
\hline
\end{tabular}

(Note: square root of the AVE on diagonals in bold) ( $\mathrm{p}>0.05$ : non-significant $(\mathrm{ns}) ;{ }^{*} \mathrm{p}<0.05, * * \mathrm{p}<0.01$ )

\subsection{Structural Model Testing}

The overall model fit was adequate, as can be seen from Table 8 . The test of overall model fit resulted in a $\chi^{2}$ value of 554.936 with a degree of freedom of 276 and a probability value of less than 0.001. The significant $\mathrm{p}$-value indicated that the absolute fit of the model was less than desirable. However, although the $\chi^{2}$ test of absolute model fit is sensitive to sample size and non-normality, a better measure of fit is chi-square $\left(\chi^{2}\right)$ over degrees of freedom. This ratio for the proposed model in this study was 2.011 , which was within the suggested 1-3 bracket (Chin \& Todd, 1995; Gefen, 2000). 
Table 8

Model Fit Summary for the Research Model

\begin{tabular}{|l|c|c|}
\hline Fit Statistics & $\begin{array}{c}\text { Recommended } \\
\text { Value }\end{array}$ & Model Value \\
\hline Chi-Square $\left(\chi^{2}\right) /$ Degree of Freedom (DF) & $\leq 3.000$ & $554.936 / 276=2.011$ \\
\hline Probability Value (p) & $>0.05$ & $<0.001$ \\
\hline Goodness-of-Fit Index (GFI) & $\geq 0.900$ & 0.901 \\
\hline Adjusted Goodness-of-Fit Index (AGFI) & $\geq 0.800$ & 0.873 \\
\hline Comparative Fit Index (CFI) & $\geq 0.900$ & 0.957 \\
\hline Tucker-Lewis Index (TLI) & $\geq 0.950$ & 0.950 \\
\hline Root Mean Square Error Approximation (RMSEA) & $\leq 0.080$ & 0.052 \\
\hline
\end{tabular}

In addition to the above-mentioned ratio, we also report some of the fit indices. Descriptive fit statistics compare a specified model to a baseline model, typically the independence model, with a view to show the superiority of the proposed model. We report the goodnessof-fit index (GFI), the adjusted GFI (AGFI), the comparative fit index (CFI), and the TuckerLewis index (TLI). Gerbing and Anderson (1988) found CFI to be one of the most stable and strongest fit indices. We also report the RMSEA (root mean square error of approximation), which measures the discrepancy per degree of freedom (Steiger \& Lind, 1980).

The CFI should be at or above 0.90 (Hoyle, 1995), while the AGFI should be at or above 0.80 (Chin \& Todd, 1995; Segars \& Grover, 1993). The CFI should be at or above 0.90 (Bentler \& Bonett, 1980; Hoyle, 1995). The TLI is more restrictive and requires a value of 0.95 or above (Hu \& Bentler, 1999). Finally, the RMSEA should be below 0.10 but has also been suggested to represent a reasonable error of approximation if it is below the more restrictive threshold of 0.08 (Browne \& Cudeck, 1993). However, Hu and Bentler (1999) suggested 0.06 to be indicative of good fit between the hypothesized model and the observed data. Table 8 illustrates these statistics, which were all found to be in accordance within the recommended levels.

Having established the relative adequacy of the model's fit, it was suitable to examine individual path coefficients corresponding to our hypotheses. This analysis is presented in Table 9. 
Table 9

Path Coefficients and Hypothesis Testing

\begin{tabular}{|c|c|c|c|c|}
\hline $\begin{array}{l}\text { Constructs' } \\
\text { Relationship }\end{array}$ & $\begin{array}{c}\text { Standardized } \\
\text { Regression Weight }\end{array}$ & $\begin{array}{l}\text { Critical } \\
\text { Ratio }\end{array}$ & $\begin{array}{c}\text { Significance } \\
\text { (p) }\end{array}$ & $\begin{array}{c}\text { Hypothesis-Supported } \\
\text { (YES|NO) }\end{array}$ \\
\hline $\mathrm{PE} \rightarrow \mathrm{AT}$ & $0.292^{*}$ & 2.185 & $\mathrm{P}=0.029$ & H1-YES \\
\hline $\mathrm{EE} \rightarrow \mathrm{AT}$ & $0.239 *$ & 1.976 & $\mathrm{p}=0.048$ & H2-YES \\
\hline $\mathrm{SI} \rightarrow \mathrm{AT}$ & $0.255^{* * *} *$ & 3.749 & $\mathrm{p}<0.001$ & H3-YES \\
\hline $\mathrm{FC} \rightarrow \mathrm{BI}$ & $0.222 * * *$ & 3.962 & $\mathrm{p}<0.001$ & H4-YES \\
\hline $\mathrm{FC} \rightarrow \mathrm{EE}$ & $0.876 * * *$ & 12.287 & $\mathrm{p}<0.001$ & H5-YES \\
\hline $\mathrm{PR} \rightarrow \mathrm{AT}$ & $-0.199 * * *$ & -3.970 & $\mathrm{p}<0.001$ & H6-YES \\
\hline $\mathrm{AT} \rightarrow \mathrm{BI}$ & $0.736 * * *$ & 11.315 & $\mathrm{P}<0.001$ & H7-YES \\
\hline $\mathrm{R}^{2}(\mathrm{BI})$ & 0.80 & \multirow{3}{*}{$\begin{array}{l}\text { (Legend: p: } \\
* * * p<0.001)\end{array}$} & \multirow{3}{*}{ significance: } & \multirow{3}{*}{$* \mathrm{p}<0.05, \quad * * \mathrm{p}<0.01$} \\
\hline $\mathrm{R}^{2}(\mathrm{AT})$ & 0.49 & & & \\
\hline $\mathrm{R}^{2}(\mathrm{EE})$ & 0.77 & & & \\
\hline
\end{tabular}

All seven hypotheses were supported. The independent constructs performance expectancy, effort expectancy, and social influence positively and significantly influenced attitude (H1, $\mathrm{H} 2$, and $\mathrm{H} 3$ ), whereas perceived risk negatively and significantly influenced attitude (H6). Moreover, facilitating conditions (H5) significantly influenced effort expectancy. In addition, facilitating conditions $(\mathrm{H} 4)$ and attitude (H7) positively impacted an individual's behavioral intention (see Table 9).

Figure 2 shows the validated UMEGA, with the path coefficients and significance of each relationship. It also demonstrates the variance of the model shown in each of the three dependent variables (effort expectancy, attitude, and behavioral intention). The variance of the model shown on behavioral intention (80\%) outperforms the variance presented by any alternative models of IS/IT adoption on behavioral intention, indicating that this is a better research model for e-government adoption than any alternative model, including the UTAUT. The proposed model is significantly different from the UTAUT model. Other studies have used the original UTAUT model developed by Venkatesh et al. (2003) as a starting point, whereas this study took the large number of constructs as a starting point and followed a similar approach as the development of the UTAUT model. For example, Weerakkody et al. (2013) took the original UTAUT model and extended it with trust to examine the adoption of 
an e-government system in the context of Saudi Arabia. Our proposed research model is significantly different because risk is used as an additional variable and attitude is used as a mediating variable.

\section{Discussion}

The current research examined the alternative models of IS/IT adoption in the perspective of a transactional e-government system called the OPCRS. Similar to the UTAUT formulation, this research integrated the fragmented theory and research on the individual acceptance of IS/IT used across the studies of e-government adoption into a unified theoretical model for egovernment adoption that captures the essential elements of previously established models (Venkatesh et al., 2003).

Firstly, we identified and theoretically reviewed the nine specific models of IS/IT adoption for determining intention and usage (see Table 2). Secondly, these models were empirically compared using the primary data gathered from respondents for a specific e-government system called the OPCRS. Thirdly, the conceptual and empirical similarities across these models and the process of formulation of the UTAUT model were used to develop the UMEGA. The items for the integrated constructs from the set of overall items collected from similar constructs were carefully selected based on their performance in terms of higher factor loadings.

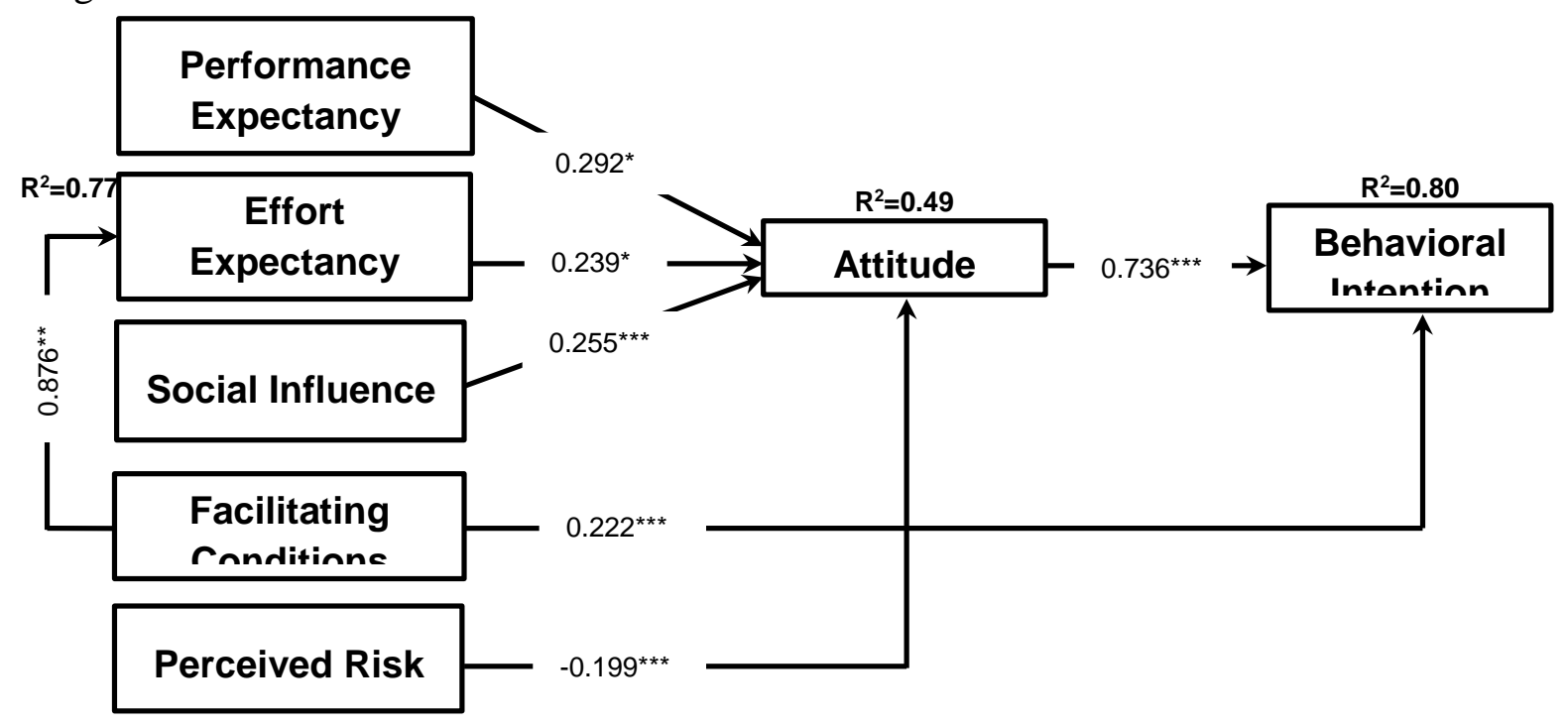




\section{Fig. 2. Validated UMEGA}

The UMEGA was empirically tested using the same dataset of the OPCRS. This test provided strong empirical support for UMEGA, which posits four direct determinants (performance expectancy, effort expectancy, social influence, and perceived risk) of attitude, two direct determinants (facilitating conditions and attitude) of behavioral intention, and one direct determinant of effort expectancy (facilitating conditions). Through this research model, we found that attitude played a strong mediating role as far as examining the adoption of an egovernment system is concerned. The findings of this research critically underscore the significance of explicitly modeling individual characteristics through the proposed UMEGA. Moreover, this model was able to account for $80 \%$ of the variance (adjusted $\mathrm{R}^{2}$ ) in behavioral intention - a substantial improvement over any of the examined nine models of IS/IT adoption.

The significant impact of performance expectancy and effort expectancy on attitude in our validated research model indicates that an individual's attitude can be determined by the level to which the e-government system may be easy to use (i.e. is less complex) and the degree to which it may prove useful and beneficial (i.e. has greater performance) to the users - in other words, the capabilities of the OPCRS might influence an individual's attitude. Davis et al. (1989) argued that within organizational settings, people form intentions toward behavior that they believe will enhance their job performance over and above whatever positive or negative feelings they might have. The authors made this argument for removing attitude from the TAM in an organizational setting, which was originally proposed by Davis (1989) with attitude as a mediating variable for the model. However, as this research argues that egovernment adoption is related to voluntary system adoption on an individual basis, attitude can well be considered part of the proposed model. Therefore, it is stated that the usefulness and benefits of such a system will initially influence an individual's positive or negative 
feelings, rather than their intention to use it. In addition, the significant and established link between perceived ease of use and attitude (see Davis et al., 1989) gives strength to the effort expectancy and attitude relationship. These relationships have been supported in a number of studies on technology adoption (e.g. Alshare \& Lane, 2011; Park et al., 2007; Pynoo et al., 2011). For example, Alshare and Lane (2011) obtained similar results on the effects of performance expectancy and effort expectancy on an individual's attitude while examining student-perceived learning outcomes on enterprise resource planning courses. Predicting secondary school teachers' acceptance and use of a digital learning environment, Pynoo et al. (2011) also found similar results for the effects of performance expectancy and effort expectancy on attitude. The authors argued that teachers held a positive attitude toward digital learning, as it was useful and easy to use. As far as e-government adoption is concerned, a reasonable number of studies (e.g. Karavasilis et al., 2010; Lau, 2004; Lu et al., 2010; Zhang et al., 2011) have supported the impact of perceived usefulness (i.e. a root variable for performance expectancy) and perceived ease of use (i.e. a root variable for effort expectancy) on attitude.

Moreover, social influence was also found to be a significant determinant of an individual's attitude. This is perhaps unsurprising because individuals may refine their attitudes based on information or stories shared by others who have already adopted similar technologies or ISs (Chiu et al., 2012; Pynoo et al., 2007; Sumak et al., 2010). As far as e-government systems such as the OPCRS are concerned, individuals can shape their positive feelings toward using them based on the success of the websites in fulfilling their purposes, impacting the people around them in the workplace, socially, and in society at large.

The research also empirically established the impact of perceived risk on behavioral intention indirectly through attitude. The significant though negative influence of perceived risk on attitude indicates that a non-adopter's apprehensions about using an e-government system 
negatively influence his or her feelings. The analysis of this relationship in the context of this research revealed that a lower perceived risk associated with the OPCRS contributed to a higher user's positive attitude to use it. The risk associated with an e-government system is also important to explore due to the fact that e-government systems are open to everyone and are available to users on an 'anywhere and anytime' basis (Karavasilis et al., 2010).

Moreover, we also found facilitating conditions to be a direct determinant of behavioral intention, as well as effort expectancy. This is perhaps not completely surprising - facilitating conditions such as arranging training programs, providing organizational and technological infrastructures, and making relevant resources available to facilitate the use of a transactional e-government system like the OPCRS are some of the mechanisms by which a government can have a significant impact on its citizens' ways of positively thinking about using the egovernment system. Moreover, the explicit modeling of attitude as a mediating variable significantly improved the explanatory power of the theoretical model - from $34 \%$ in the UTAUT to $80 \%$ in the UMEGA - on behavioral intention. The significant impact of facilitating conditions on effort expectancy indicates that the technical support and infrastructure provided by the government to its users led to easy access to the system. The high overall variance $(77 \%)$ explained by the only variable facilitating conditions on effort expectancy indicates the degree of importance of the technical resources and infrastructure provided by the government in order to ensure easier access to the OPCRS to obtain a PAN card only with a few clicks, rather than spending days reaching out to the concerned government office.

Finally, the strong and significant impact of the mediating construct attitude on behavioral intention implies that a user might intend to use the OPCRS based on the strength of their attitude. A number of studies on technology adoption in general (e.g. Chiu et al., 2012; Park et al., 2007; Venkatesh et al., 2011) and on e-government adoption in particular (e.g. Hung et 
al., 2006; Lau, 2004; Lu et al., 2010; Rana \& Dwivedi, 2015) have acknowledged this strong and significant relationship.

\subsection{Limitations and Future Research}

Although we systematically developed and validated the UMEGA based on the data gathered for an e-government system and compared it with alternative models of IS/IT adoption, this research was not without certain limitations. Firstly, the exploration of the UMEGA was validated with regard to the non-adopters of the OPCRS. The model was validated using the data gathered from non-adopters of the e-government system in our work, and therefore we did not include use behavior in our model. Hence, caution needs to be taken when generalizing the findings to adopters of the system. Extending and validating the model for adopters and including this construct are recommended as further research. For this, the model should be extended by including the actual usage variable when the data for validating the extended model is gathered from adopters.

Secondly, in the course of choosing the higher loading items for the core determinants (performance expectancy, effort expectancy, social influence, and facilitating conditions) of attitude and behavioral intention, we found that the items of some constructs representing the specific model were not represented in the proposed model. For example, the items of output expectation from SCT, of performance expectancy from UTAUT, of complexity from the model of PC utilization in effort expectancy, and of image from IDT in social influence were not considered for the proposed model. Therefore, the measures for the UMEGA should be viewed as preliminary, and future research should be aimed at more fully developing and validating appropriate scales for each of the constructs and revalidating the model presented here with new measures (Venkatesh et al., 2003).

Thirdly, this research used a mixed sample of employees, students, self-employed individuals, and pensioners to validate the e-government-specific unified model. Future 
research could possibly look at only the employees' perspective to see the significance of the relationships and the performance of the UMEGA.

Fourthly, this study performed an empirical investigation of the proposed model by considering one-time cross-sectional data collected from non-adopters from seven different cities of a country. Future research could validate the performance of the proposed model using longitudinal data. The longitudinal study could possibly be more feasible by using the data gathered from employees, which could be linked with the previous suggestion for future research.

Finally, while the variance ( $80 \%$ ) explained by the UMEGA on behavioral intention is higher than in any alternative models of IS/IT adoption, further work should identify and test additional boundary conditions of the model in an attempt to provide an even richer understanding of e-government adoption.

\subsection{Theoretical Contributions}

The original UTAUT model can explain an individual's acceptance and use of IS/IT using two constructs (performance expectancy and effort expectancy) that may be considered to represent the technological context and another two (social influence and facilitating conditions) that may be considered to represent the implementation context (Schaper \& Pervan, 2007). However, the individual's characteristics are not included in the UTAUT model. In the synthesis of prior research, we found that substantial importance had been placed on the individual's attitude toward IS/IT (e.g. Alshare \& Lane, 2011; Sumak et al., 2010).

This study proposed and tested a theoretical model with attitude as a variable representing the individual context. The analyses revealed that our proposed theoretical model performed much better than any alternative model, including the UTAUT itself. The possible reason for this was the selection of better-suited measures for the UTAUT constructs in the e- 
government context and using them to devise the model, rather than depending on the original measures of the UTAUT, which were used for technology adoption in the organizational context. Moreover, the proposed model included perceived risk to give a sense of the inclusion of an e-government-specific construct into the UMEGA. As none of the research on e-government systems adoption has developed a unified model, as has been formulated here, the present research contributes to the existing theoretical knowledge on egovernment adoption.

Above all, the presence of perceived risk as an e-government-specific exogenous variable strengthens the performance of the model. This additional construct, along with the core constructs of the UMEGA, is a theoretical contribution to any framework-development-based research on e-government systems adoption. However, future research could test more constructs (such as trust, self-efficacy, anxiety, etc.) with this model to test its performance under diverse conditions. For example, the significance of trust in effective governance suggests that the development of a model based on citizens' trust is both timely and practical (Kim, 2005). Some scholars have equated trust with behaviors that convey risk-taking (e.g. Lewis \& Weigert, 1985). As per Mayer et al.'s (1995) formulation, the distinction between trust and risk-taking reflects the difference between a willingness to be vulnerable and actually becoming vulnerable. Risk-taking, therefore, stands as the most proximal behavior outcome or expression of trust (Mayer et al., 1995; Ross \& LaCroix, 1996).

In the current research, perceived risk, which is one of the risk-taking perceptions, was considered part of the proposed unified model, which was validated as an important factor in the proposed model. Hence, the proposed research model provides great strength to the trustworthiness literature and models of public administration in general. Relationships such as 'facilitating conditions $\rightarrow$ effort expectancy', although considered in some studies on technology adoption, have not been considered either as part of the UTAUT or in further 
empirical extensions of this model in e-government systems adoption, and hence the present study offers new insights regarding individual attitudes and intentions relating to the adoption of such a system. The relationship indicates that the available resources, knowledge, and opportunities relating to the system make it easier to use, and hence users will be more likely to adopt it. In addition, the performance of the proposed research model indicates that moderators may not be universally applicable to all contexts and hence run the danger of being non-relevant in certain settings. Our analysis also shows that it may be beneficial and significant to theorize and validate the direct effects, rather than considering moderators.

The UMEGA is a parsimonious and relatively simpler model that makes a trade-off between complexity and explanative power. As far as its complexity is concerned, this has been enormously reduced due to the removal of moderators, whereas its explanatory power (variance in behavioral intention of $80 \%$ ) has been notably enhanced in comparison with the UTAUT model (variance in behavioral intention of $69 \%$ ). This immense increase in the explanatory power of the model has primarily happened due to its simplicity and introducing attitude as a mediating variable. Introducing attitude in the model was extremely important, as it represents a citizen-centric voluntary e-government system. The UTAUT model in its original form could not perform as expected, possibly due to a couple of reasons. Firstly, this model was essentially developed for the organizational context and its items would therefore not be suitable for individual contexts. Secondly, in its original form, the model does not include attitude as a mediating variable, as it has no role to play in the mandatory settings. However, the theoretical contribution of this research takes care of both these limitations in the proposed model (the UMEGA) and has replaced the original items of the UTAUT with the most appropriate items in the e-government context, as well as introducing attitude as a mediating variable because of the voluntary nature of the e-government system. While this model can still be criticized for not including moderators, the proposed model is applicable to 
the majority of generic situations where moderators do not make sense. Moreover, the model can also be criticized for the fact that we only looked at adoption, whereas other dependent variables like success and technology fit were not investigated.

\subsection{Implications for Practice}

The findings of this research indicated that attitude played a decisive role in an individual's intention to adopt and use the OPCRS. Specifically, attitude was found to be a strong determinant of behavioral intention, which implies that the concerned government organization implementing the OPCRS may find it beneficial to shape individuals' attitudes using policy measures like providing help desks and/or training programs to users to effectively use the system, in order to influence their further intentions toward using the system.

We found performance expectancy and effort expectancy to be the antecedents of attitude. This implies that individuals attribute substantial importance to the technological extent to which an e-government system is useful and easy to use. Therefore, designers, system analysts, and developers responsible for the design and development of e-government systems should focus more on minimizing the complexities associated with exploration and use of the system, if there are any, and the usefulness of the system, such that the acceptance and use of such systems may be managed more successfully.

Possible ways of achieving these objectives may include wider and more accurate representation of user requirements to system analysts, designers, and developers or selecting and benchmarking the system against other e-government systems that are more consistent with user requirements and have wide acceptance, as well as the effective communication of the system's capabilities through product brochures, live demonstrations, and success stories (e.g. Alshare \& Lane, 2011; Koh et al., 2010; San Martín \& Herrero, 2012; Pynoo et al., 2011). 
An alternative way to develop a widely acceptable and easy-to-use system can be in consultation with experienced designers, systems analysts, and software developers who possess good experience of developing such systems and understand users' issues with and expectations of such systems. In addition, the development of such initiatives could be strengthened by engaging citizens in online policy dialogues and promoting citizens' empowerment and active participation through community organizations at the neighborhood level (Ho, 2002). The best and most recent example of such a system in the Indian context is the MyGov Digital India web portal. This e-government portal invites Indian citizens to be active partners in building national programs (e.g. caring for the disabled, cleaning the Ganga (a sacred river in Hindu mythology), consumer protection and internal trade, administrative reforms and public grievances, etc.) and in participating through discussions, polls, blogs, and talks (MyGov, 2016). The government could make arrangements to promote the system's usefulness and benefits through the brick-and-mortar locations that people physically visit to obtain their PAN cards. The government could do this by distributing pamphlets and posters at the physical locations.

The national e-governance plan (NeGP) was formulated by the Department of Electronics and Information Technology (DEITY) and the Department of Administrative Reforms and Public Grievance (DARPG) in 2006. It aims to improve the delivery of government services to citizens and businesses, with the vision of making all government services available to the common people in their localities through the CSC outlets and ensuring the efficiency, transparency, and reliability of such services at affordable costs to realize the basic needs of the common people. Based on the lessons learned (from the difficulty of using the complex and ineffective e-government system, the lack of government departments to take ownership of the e-government projects, the lack of proper coordination among supporting departments, the lack of good online service delivery, the lack of an adequate supporting infrastructure for 
ICT (such as electricity, telephones, etc.), the lack of trust among citizens in using the egovernment system, the lack of relevant content in the local language, etc.) from the past and experience from some successful e-government implementations, the NeGP proposed a public-private partnership (PPP) model, which is adopted wherever feasible to enlarge the resource pool without compromising on the security aspects (NeGP, 2015).

The state and the central governments should effectively use this policy to bring in moreexperienced expert employees to design and develop the specific e-government portals from a large pool of such resources, considering the PPP model. The government could, in fact, spend more money to develop resources exactly as per their requirements, and private-public collaboration would allow governments at different levels to bring in skilled analysts and designers to develop portals that can meet stakeholders' expectations closely. Such collaborations would not only enhance the quality of the e-government system and make it easier for citizens to use but also enhance the system's effectiveness and usefulness.

We also found that social influence had a direct impact on attitude and that facilitating conditions had a direct impact on behavioral intention. This suggests that individuals may place importance on facilitating conditions such as help desks, technological and infrastructural resources, and training programs, as well as the experiences of other individuals in using the e-government system in question. Hence, the concerned government organizations or departments should consider equipping their common training program centers (such as CSCs) with adequate infrastructural and technological facilities and should identify champions for providing the prerequisite training to users so that they can be positively motivated toward using relatively new and useful e-government systems, like the OPCRS. The concerned government departments and/or officials may proactively manage the social influence that could be exerted on individuals by organizing forums for sharing best use practices, introducing champions who are enthused about diffusing awareness and 
the benefits of the system and can generate positive word of mouth, and planning countermeasures for any negative feedback (Chiu et al., 2012; Pynoo et al., 2007; Sumak et al., 2010). The role of the PPP model also cannot be ignored as far as the improvement of infrastructure and recognizing and developing more project champions are concerned.

As private software development companies are the established players in developing appropriate infrastructures and nurturing human resources, government collaboration with such companies would support the development and efficient implementation of an egovernment-oriented infrastructure and would produce champions who can diffuse the widespread adoption of such services to the wider community in society. As the NeGP initiative is also aimed at identifying successful projects and replicating them with the needed customization, the policymakers could plan to effectively implement the OPCRS by using such successfully implemented systems as its base. Moreover, the government needs to strengthen its infrastructure as prescribed in the NeGP initiatives, including State-Wise Area Networks (SWANs), State Data Centers (SDCs), CSCs, and Electronic Service Delivery Gateways (NeGP, 2015).

In addition, the negative and significant influence of perceived risk on attitude indicates that the government should promote the security and privacy measures being adopted to save its citizens from any unwanted cases of security breaches and cyber-fraud. The NeGP recommendations have already advocated that all its suggested implementations need to take place without affecting or compromising on the security aspects. This clearly indicates that security is a major concern to be considered as part of successfully implementing an egovernment initiative. An easy way to spread such awareness could be possibly through brick-and-mortar locations using pamphlets and posters, as well as print and broadcast media. In addition, the government must also create a technology environment that is ready for implementing the e-government initiative with success. Citizens with frequent access to such 
services at home must be trained in cyber-security. This could be achieved through champions who create awareness among the people in their localities. The CSCs must be fully equipped with modern security software that can easily prevent cyber-attacks. The government should also formulate a strict policy where the perpetrators of such crimes are severely punished.

\section{Conclusion}

The adoption literature is fragmented, with many splinters of knowledge, which leaves policymakers in a void about which model is suitable and should be used. Adoption models were selected that were not e-government specific. Based on the literature, a comprehensive adoption model was created, which included constructs from the TAM, the TPB, the DOI, and the UTAUT. These models can be criticized for not considering e-government-specific factors, including trust, risk, security, and privacy. Nine well-known theoretical models of IT adoption were evaluated, and 29 different constructs were identified and tested. The adoption models were analyzed using data about the OPCRS, and it was found that these models underperformed, as fit indices, path coefficients, or both at some point or the other did not perform as per the recommended levels. The UMEGA was developed, which includes the constructs perceived usefulness, relative advantage, perceived ease of use, subjective norm, social factor, perceived behavioral control, facilitating conditions, attitude, perceived risk, and behavioral intention. Researchers working in the field of IS/IT adoption should take this comprehensive model into account.

This research first critically reviewed the alternative models of IS/IT adoption using the primary data gathered from the non-adopters of the OPCRS. Models directly derived from the UTAUT often neglect e-government-dependent constructs. Although the UTAUT, which has been found to be a recommended model in most of its implementations, was found to have all significant relationships, except performance expectancy on behavioral intention, the model 
extremely underperformed and possibly demonstrated the worst performance among all the examined models of IS/IT adoption.

In the alternative theoretical model, we proposed and emphasized the need for the inclusion of attitude as a mediating variable. The unified model was used as a base because it tacitly represents all other dominant models of IS/IT adoption. Specifically, we modeled attitude to mediate the effects of core constructs such as performance expectancy, effort expectancy, and social influence on behavioral intention. The remodeling of the UTAUT was done due to the fact that it was primarily theorized for the organizational context, whose perspective is different to its possible theorization for the e-government context.

The UMEGA is a parsimonious model due to the removal of moderators, and its explanatory power (variance in behavioral intention of $80 \%$ ) has been notably enhanced in comparison with the UTAUT model (variance in behavioral intention of $69 \%$ ). This immense increase in the explanatory power of the model has primarily happened due to its simplicity and introducing attitude as a mediating variable. Introducing attitude in the model was extremely important, as the model represents a citizen-centric voluntary e-government system. The performance of the UMEGA, incorporating a different and more suitable set of items (measured on the basis of their factor loading values) from the UTAUT, assimilating perceived risk as an e-government-specific construct and considering attitude as a mediating variable, was found to be sensibly better, and the variance explained by the model in behavioral intention outperformed all the alternative models of IS/IT adoption. Hence, the empirical investigation shows that the proposed model that reframed the propositions of the UTAUT model is a more meaningful alternative for understanding e-government systems adoption.

This research shows that IS/IT models and concepts should not be indiscriminately copied to the area of e-government. Constructs developed for the technology adoption model at the 
organizational level are likely not appropriate for the e-government context. This confirms that e-government is a domain on its own and that its idiosyncratic characteristics should be taken into account. The UMEGA can be used in e-government research by taking the egovernment-specific context into account. The model should be used by researchers in the egovernment community as a substitute for alternative theoretical models (e.g. the TRA, the TAM, the TPB, the DTPB, the DOI, etc.) of IS/IT adoption, as it effectively includes essential constructs from all such models, including the UTAUT. In addition, researchers are also suggested to develop new scales and constructs, such as self-efficacy, anxiety, security, and privacy, which are e-government specific. Developments like the mandatory use of services might also influence these models. In addition, differentiating between types of citizens, like students, pensioners, public servants, self-employed individuals, and employees of large companies, could help to advance our insight. As further research, we recommend a meta-synthesis of existing models to analyze the constructs. Although this would not be possible for all models, given that they are not covered in e-government research, this could help to advance this area.

\section{References}

Aboelmaged, M.G. (2010). Predicting e-procurement adoption in a developing country: An empirical integration of technology acceptance model and theory of planned behaviour. Industrial Management \& Data Systems, 110(3), 392-414.

Abu-Shanab, E., \& Pearson, J. (2009). Internet banking in Jordan: an Arabic instrument validation process. The International Arab Journal of Information Technology, 6(3), 235-244.

Abu-Shanab, E., Al-Rub, S.A., \& Nor, K.M. (2010). Obstacles Facing the Adoption of EGovernment Services in Jordan. Journal of E-Governance, 33(1), 35-47.

Aggelidis, V.P. \& Chatzoglou, P.D. (2009). Using a modified technology acceptance model in hospitals. International Journal of Medical Informatics, 78(2), 115-126.

Ajzen, I. (1991). The theory of planned behavior. Organizational Behavior and Human Decision Processes, 50(2), 179-211. 
Ajzen, I. \& Fishbein, M. (1980). Understanding attitudes and predicting social behavior. Englewood Cliffs, NJ: Prentice-Hall.

Akman, I., Yazici, A., Mishra, A., \& Arifoglu, A. (2005). E-government: A global view and an empirical evaluation of some attributes of citizens. Government Information Quarterly, 22(2), 239-257.

Al-Adawi, Z., Yousafzai, S. \& Pallister, J. (2005). Conceptual model of citizen adoption of egovernment. The Second International Conference on Innovations in Information Technology, 1-10.

AllOnMoney (2014). 10 reasons why PAN card is important in India. Accessed from http://www.allonmoney.com/information/why-you-should-have-pan-card/ on $17^{\text {th }}$ July 2015.

Alrawashdeh, T.A., Muhairat, M.I., \& Alqatawnah, S.M. (2012). Factors affecting acceptance of web-based training system: Using extended UTAUT and structural equation modeling. arXiv preprint arXiv: 1205.1904.

Al-Sebie, M. \& Irani, Z. (2005). Technical and organisational challenges facing transactional e-government systems: An empirical study. Electronic Government: An International Journal, 2(3), 247-276.

Alshare, K.A. \& Lane, P.L. (2011). Predicting student-perceived learning outcomes and satisfaction in ERP courses: An empirical investigation. Communications of the Association for Information Systems, 28(1), 572-584.

Anderson, J.C., \& Gerbing, D.W. (1988). Structural equation modeling in practice: A review and recommended two-step approach. Psychological Bulletin, 103(3), 411-423.

Anthopoulos, L.G., Siozos, P., \& Tsoukalas, I.A. (2007). Applying participatory design and collaboration in digital public services for discovering and re-designing e-Government services. Government Information Quarterly, 24(2), 353-376.

Bagozzi, R.P. (1981). Attitudes, intentions, and behavior: A test of some key hypotheses. Journal of Personality and Social Psychology, 41(4), 607-627.

Bandura, A. (1986). The explanatory and predictive scope of self-efficacy theory. Journal of Social and Clinical Psychology, 4(3), 359-373.

Barclay, D.W. \& Smith, J.B. (1997). The effects of organizational differences and trust on the effectiveness of selling partner relationships. Journal of Marketing, 61(1), 3-21.

Belanger, F. \& Carter, L. (2008). Trust and risk in e-government adoption. The Journal of Strategic Information Systems, 17(2), 165-176.

Bentler, P. \& Bonett, D. (1980). Significance tests and goodness of fit in the analysis of covariance structures. Psychological Bulletin, 88(3), 588-606. 
Bertot, J.C., Jaeger, P.T., \& Grimes, J.M. (2012). Promoting transparency and accountability through ICTs, social media, and collaborative e-government. Transforming Government: People, Process and Policy, 6(1), 78-91.

Bhatnagar, S.C. (2000). Social implications of information and communication technology in developing countries: Lessons from Asian success stories. The Electronic Journal of Information Systems in Developing Countries, 1(4), 1-9.

Bobbitt, L.M. \& Dabholkar, P.A. (2001). Integrating attitudinal theories to understand and predict use of technology-based self-service: The Internet as an illustration. International Journal of Service Industry Management, 12(5), 423-450.

Bonsón, E., Torres, L., Royo, S., \& Flores, F. (2012). Local e-government 2.0: Social media and corporate transparency in municipalities. Government Information Quarterly, 292, 123132.

Brancheau, J.C. \& Wetherbe, J.C. (1990). The adoption of spreadsheet software: Testing innovation diffusion theory in the context of end-user computing. Information Systems Research, 1(2), 115-143.

Browne, M.W. \& Cudeck, R. (1993). Alternative ways of assessing model fit. In K.A. Bollen and J.S. Long (eds.). Testing Structural Equation Models. Newbury Park, CA: Sage, 136-162.

Carter, L. \& Belanger, F. (2005). The utilization of e-government services: Citizen trust, innovation and acceptance factors. Information Systems Journal, 15(1), 5-25.

Carter, L., \& Schaupp, L.C. (2009). Relating Acceptance and Optimism to E-File Adoption. International Journal of Electronic Government Research, 5(3), 62-74.

Carter, L., Schaupp, L.C., Hobbs, J., \& Campbell, R. (2012). E-government utilization: Understanding the impact of reputation and risk. International Journal of Electronic Government Research, 8(1), 83-97.

Cases, A.-S. (2002). Perceived risk and risk-reduction strategies in Internet shopping. The International Review of Retail, Distribution and Consumer Research, 12(4), 375-394.

Chan, C.M., Hackney, R., Pan, S.L., \& Chou, T.C. (2011). Managing e-government system implementation: A resource enactment perspective. European Journal of Information Systems, 20(5), 529-541.

Chen, M.F. \& Lu, M.T.Y. (2011). Modeling e-coupon proneness as a mediator in the extended TPB model to predict consumers' usage intentions. Internet Research, 21(5), 508526.

Chin, W.W. \& Todd, P.A. (1995). On the use, usefulness, and ease of use of structural equation modeling in MIS research: A note of caution. MIS Quarterly, 19(2), 237-246. 
Chiu, C.M., Wang, E.T., Fang, Y.H., \& Huang, H.Y. (2014). Understanding customers' repeat purchase intentions in $\mathrm{B} 2 \mathrm{C}$ e-commerce: The roles of utilitarian value, hedonic value and perceived risk. Information Systems Journal, 24(1), 85-114.

Chiu, Y.T.H., Lee, W.I., Liu, C.C., \& Liu, L.Y. (2012). Internet lottery commerce: An integrated view of online sport lottery adoption. Journal of Internet Commerce, 11(1), 68-80.

Colesca, S.E. (2009). Increasing e-trust: A solution to minimize risk in e-government adoption. Journal of Applied Quantitative Methods, 4(1), 31-44.

Compeau, D.R. \& Higgins, C.A. (1995a). Application of social cognitive theory to training for computer skills. Information Systems Research, 6(2), 118-143.

Compeau, D.R. \& Higgins, C.A. (1995b). Computer self-efficacy: Development of a measure and initial test. MIS Quarterly, 19(2), 189-211.Compeau, D.R., Higgins, C.A., \& Huff, S. (1999). Social cognitive theory and individual reactions to computing technology: A longitudinal study. MIS Quarterly, 23(2), 145-158.

Cook, M.E. (2000). What citizens want from e-government. Center for Technology in Government. University at Albany, SUNY.

Cooper, R.B. \& Zmud, R.W. (1990). Information technology implementation research: A technological diffusion approach. Management Science, 36(2), 123-139.

Coursey, D. \& Norris, D.F. (2008). Models of e-government: Are they correct? An empirical assessment. Public Administration Review, 68(3), 523-536.

Cox, J. (2012). Information systems user security: A structured model of the knowing-doing gap. Computers in Human Behavior, 28(5), 1849-1858.

Davis, F.D. (1989). Perceived usefulness, perceived ease of use, and user acceptance of information technology. MIS Quarterly, 13(3), 319-339.

Davis, F.D., Bagozzi R.P., \& Warshaw, P.R. (1989). User acceptance of computer technology: A comparison of two theoretical models. Management Science, 35(8), 982-1002.

DeLone, W.H. \& McLean, E.R. (1992). Information systems success: The quest for the dependent variable. Information Systems Research, 3(1), 60-95.

DeLone, W.H. \& McLean, E.R. (2003). The DeLone and McLean model of information systems success: A ten-year update. Journal of Management Information Systems, 19(4), 930.

Dwivedi, Y.K., Weerakkody, V., \& Janssen, M. (2012). Moving towards maturity: Challenges to successful e-government implementation and diffusion. The Data Base for Advances in Information Systems, 42(4), 11-22. 
Eckhardt, A., Laumer, S., \& Weitzel, T. (2009). Who influences whom? Analyzing workplace referents' social influence on IT adoption and non-adoption. Journal of Information Technology, 24(1), 11-24.

Egea, J.M.O. \& González, M.V.R. (2011). Explaining physicians' acceptance of EHCR systems: An extension of TAM with trust and risk factors. Computers in Human Behavior, 27(1), 319-332.

Field, A. (2005). Discovering statistics using SPSS. Thousand Oaks, CA: Sage.

Fishbein, M. \& Ajzen, I. (1975). Belief, attitude, intention and behavior: An introduction to theory and research. Reading, MA: Addison-Wesley.

Foon, Y.S. \& Fah, B.C.Y. (2011). Internet banking adoption in Kuala Lumpur: An application of UTAUT model. International Journal of Business and Management, 6(4), 161167.

Fornell, C., \& Larcker, D.F. (1981). Evaluating structural equation models with unobservable variables and measurement error. Journal of Marketing Research, 18(1), 39-50.

Gauld, R., Goldfinch, S., \& Horsburgh, S. (2010). Do they want it? Do they use it? The 'demand-side' of e-government in Australia and New Zealand. Government Information Quarterly, 27(2), 177-186.

Gefen, D. (2000). E-commerce: The role of familiarity and trust. Omega: The International Journal of Management Science, 28(6), 725-737.

Gefen, D., Karahanna, E., \& Straub, D.W. (2003). Trust and TAM in online shopping: An integrated model. MIS Quarterly, 27(1), 51-90.

Gerbing, D.A. \& Anderson, J.C. (1992). Monte Carlo evaluations of goodness of fit indices for structural equation models. Sociological Methods and Research, 2(2), 132-160.

Ghosh, P. (2013). How many people in India pay income tax? Hardly anyone. International Business Times. Accessed from http://www.ibtimes.com/how-many-people-india-payincome-tax-hardly-anyone-1294887 on $7^{\text {th }}$ January 2015.

Gilbert, D., Balestrini, P., \& Littleboy, D. (2004). Barriers and benefits in the adoption of egovernment. International Journal of Public Sector Management, 17(4/5), 286-301.

Goodhue, D.L. (1995). Understanding user evaluations of information systems. Management Science, 41(12), 1827-1844.

Goodhue, D.L. \& Thompson, R.L. (1995). Task-technology fit and individual performance. MIS Quarterly, 19(2), 213-236.

Hackney, R., Jones, S., \& Losch, A. (2007). Towards an e-government efficiency agenda: The impact of information and communication behaviour on e-reverse auctions in public sector procurement. European Journal of Information Systems, 16(2), 178-191. 
Hair, J.F., Anderson, R.E., Tatham, R.L., \& Black, W.C. (1992). Multivariate data analysis with readings. $3^{\text {rd }}$ edition. New York, NY: Macmillan Publishing Company.

Hardy, C.A. \& Williams, S.P. (2011). Assembling e-government research designs: A transdisciplinary view and interactive approach. Public Administration Review, 71(3), 405413.

Harrison, D. A., Mykytyn Jr, P. P., \& Riemenschneider, C. K. (1997). Executive decisions about adoption of information technology in small business: Theory and empirical tests. Information Systems Research, 8(2), 171-195.

Heeks, R. \& Bailur, S. (2007). Analyzing e-government research: Perspectives, philosophies, theories, methods and practice. Government Information Quarterly, 24(2), 243-265.

Ho, A.T.-K. (2002). Reinventing local governments and the e-government initiative. Public Administration Review, 62(4), 434-444.

Horst, M., Kuttschreuter, M., \& Gutteling, J.M. (2007). Perceived usefulness, personal experiences, risk perception and trust as determinants of adoption of e-government services in the Netherlands. Computers in Human Behavior, 23(4), 1838-1852.

Howard, G.S. \& Smith, R.D. (1986). Computer anxiety in management: Myth or reality? Communications of the ACM, 29(7), 611-615.

Hoyle, R.H. (1995). The structural equation modeling approach: Basic concepts and fundamental issues. Thousand Oaks, CA: Sage Publications.

Hu, L.-T. \& Bentler, P.M. (1999). Cutoff criteria for fit indexes in covariance structure analysis: Conventional criteria versus new alternatives. Structural Equation Modeling, 6(1), $1-55$.

Huang, Z. \& Bwoma, P.O. (2003). An overview of critical issues of e-government. IACIS, 164-170.

Huff, S.L. \& Munro, M.C. (1985). Information technology assessment and adoption: A field study. MIS Quarterly, 9(4), 327-338.

Hung, S.-Y., Chang, C-M., \& Kuo, S.-R. (2013). User acceptance of mobile e-government services: An empirical study. Government Information Quarterly, 30(1), 33-44.

Hung, S.Y., Chang, C.M., \& Yu, T. (2006). Determinants of user acceptance of the egovernment services: The case of online tax filing and payment system. Government Information Quarterly, 23(1), 97-122.

Hung, S.-Y., Tang, K.-Z., Chang, C.-M., \& Ke, C.-D. (2009). User acceptance of intergovernmental services: An example of electronic document management system. Government Information Quarterly, 26(2), 387-397. 
Igbaria, M. \& Chakrabarti, A. (1990). Computer anxiety and attitudes towards microcomputer use. Behaviour \& Information Technology, 9(3), 229-241.

Igbaria, M. \& Parasuraman, S. (1989). A path analytic study of individual characteristics, computer anxiety and attitudes toward microcomputers. Journal of Management, 15(3), 373388.

IGP (2014). Indian Government Portal. Accessed from http://india.gov.in/egovernance/initiatives on $25^{\text {th }}$ September 2014.

INDG (2014). E-governance in India: Transforming service delivery system. Accessed from http://www.indg.in/e-governance on $25^{\text {th }}$ September 2014.

Irani, Z., Elliman, T., \& Jackson, P. (2007). Electronic transformation of government in the UK: A research agenda. European Journal of Information Systems, 16(4), 327-335.

Jorgensen, D.J., \& Cable, S. (2002). Facing the challenges of e-government: A case study of the city of Corpus Christi, Texas. SAM Advanced Management Journal, 67(3), 15-30.

Joseph, R.C. (2013). A structured analysis of e-government studies: Trends and opportunities. Government Information Quarterly, 30(4), 435-440.

Karavasilis, I., Zafiropoulos, K., \& Vrana, V. (2010). Extending TAM to understand egovernance adoption by teachers in Greece. In M.D. Lytras, P.O. de Pablos, A. Ziderman, A. Roulstone, H. Maurer, \& J.B. Imber (eds.). WSKS 2010, Part II, CCIS 112, 57-68.

Kim, H.J., Pan, G., \& Pan, S.L. (2007). Managing IT-enabled transformation in the public sector: A case study on e-government in South Korea. Government Information Quarterly, $24(2), 338-352$.

Kim, D.J., Ferrin, D.L., \& Rao, H.R. (2008). A trust-based consumer decision-making model in electronic commerce: The role of trust, perceived risk, and their antecedents. Decision Support Systems, 44(2), 544-564.

Kim, S.E. (2005). The role of trust in the modern administrative state: An integrative model. Administration \& Society, 37(5), 611-635.

Kim, T.T., Suh, Y.K., Lee, G., \& Choi, B.G. (2010). Modelling roles of task-technology fit and self-efficacy in hotel employees' usage behaviours of hotel information systems. International Journal of Tourism Research, 12(6), 709-725.

Kim, Y.J., Chun, J.U., \& Song, J. (2009). Investigating the role of attitude in technology acceptance from an attitude strength perspective. International Journal of Information Management, 29(1), 67-77.

Koh, C.E., Prybutok, V.R., Ryan, S.D., \& Wu, Y.A. (2010). A model for mandatory use of software technologies: An integrative approach by applying multiple levels of abstraction of 
informing science. Informing Science: The International Journal of an Emerging Transdiscipline, 13, 177-203.

Kumar, T. \& Misra, H. (2007). Decentralization and e-government services in Indian context: Case based study in Gujarat. In G.P. Sahu (ed.). Adopting e-governance. New Delhi: GIFT Publishing, 1-10.

Kwon, T.H. \& Zmud, R.W. (1987). Unifying the fragmented models of information systems implementation. In R.J. Boland \& R.A. Hirschheim (eds.). Critical issues in information systems research. New York, NY: Wiley, 227-251.

Lau, A.S.M. (2004). Strategies to encourage the adoption of G2C e-government services in Hong Kong. Electronic Government: An International Journal, 1(3), 273-292.

Lean, O.K., Zailani, S., Ramayah, T., \& Fernando, Y. (2009). Factors influencing intention to use government services among citizens in Malaysia. International Journal of Information Management, 29(6), 458-475.

Lee, V. \& Lin, S.J. (2008). Podcasting acceptance on campus: An extension of the UTAUT Model. DIGIT 2008 Proceedings, Paris, France.

Leonard-Barton, D. \& Deschamps, I. (1988). Managerial influence in the implementation of new technology. Management Science, 34(10), 1252-1265.

Lewis, J. D. \& Weigert, A. (1985). Trust as a social reality. Social Forces, 63(4), 967-985.

Lin, F., Fofanah, S.S., \& Liang, D. (2011). Assessing citizen adoption of e-government initiatives in Gambia: A validation of the technology acceptance model in information systems success. Government Information Quarterly, 28(2), 271-279.

Lu, C.-T., Huang, S.-Y., \& Lo, P.-Y. (2010). An empirical study of on-line tax filing acceptance model: Integrating TAM and TPB. African Journal of Business Management, $4(5), 800-810$.

Lu, H.P., Hsu, C.L., \& Hsu, H.Y. (2005). An empirical study of the effect of perceived risk upon intention to use online applications. Information Management \& Computer Security, 13(2), 106-120.

Luna-Reyes, L.F., Gil-Garcia, J.R., \& Romero, G. (2012). Towards a multidimensional model for evaluating electronic government: Proposing a more comprehensive and integrative perspective. Government Information Quarterly, 29(3), 324-334.

Luo, X., Li, H., Zhang, J., \& Shim, J. P. (2010). Examining multi-dimensional trust and multi-faceted risk in initial acceptance of emerging technologies: An empirical study of mobile banking services. Decision Support Systems, 49(2), 222-234. 
McLeod Jr., A.J., \& Pippin, S.E. (2009). Security and Privacy Trust in E-Government: Understanding System and Relationship Trust Antecedents. 42 ${ }^{\text {nd }}$ Hawaii International Conference on System Sciences, 1-10.

Mathieson, K. (1991). Predicting user intentions: Comparing the technology acceptance model with the theory of planned behavior. Information Systems Research, 2(3), 173-191.

Mayer, R.C., Davis, J.H., \& Schoorman, F.D. (1995). An integrative model of organizational trust. Academy of Management Review, 20(3), 709-734.

McDermott, P. (2010). Building open government. Government Information Quarterly, 27(4), 401-413.

Moon, M.J. (2002). The evolution of e-government among municipalities: Rhetoric or reality? Public Administration Review, 62(4), 424-433.

Moore, G.C. \& Benbasat, I. (1991). Development of an instrument to measure the perceptions of adopting an information technology innovation. Information Systems Research, 2(3), 192-222.

Morrow, P.C., Preix, E.R., \& McElroy, J.C. (1986). Attitudinal and behavioral correlates of computer anxiety. Psychological Reports, 59(3), 1199-1204.

MyGov (2014). MyGov - Citizen participation towards good governance. Accessed from http://india.gov.in/spotlight/mygov-citizen-participation-towards-good-governance on $25^{\text {th }}$ September 2014.

MyGov (2016). MyGov - Meri Sarkar: Government of India. Accessed from https://www.mygov.in/group/digital-india/ on $16^{\text {th }}$ October 2016.

NeGP (2015). National e-governance plan. Accessed from http://india.gov.in/egovernance/national-e-governance-plan on $21^{\text {st }}$ July 2015.

Netemeyer, R.G., Johnston, M.W., \& Burton, S. (1990). Analysis of role conflict and role ambiguity in a structural equations framework. Journal of Applied Psychology, 75(2), 148157.

Nielsen, M.M. (2016). E-governance and stage models: Analysis of identified models and selected Eurasian experiences in digitising citizen service delivery. Electronic Government: An International Journal, 12(2), 107- 141.

Nkohkwo, Q.N.A. \& Islam, M.S. (2013). Challenges to the successful implementation of egovernment initiatives in Sub-Saharan Africa: A literature review. Electronic Journal of $e$ Government, 11(2), 253-267.

Norris, D.F. \& Lloyd, B.A. (2006). The scholarly literature on e-government: Characterizing a nascent field. International Journal of Electronic Government Research, 2(4), 40-56. 
Norris, D.F. \& Moon, M.J. (2005). Advancing e-government at the grassroots: Tortoise or hare? Public Administration Review, 65(1), 64-75.

Nunnaly, J. (1978). Psychometric theory. New York, NY: McGraw-Hill.

Parasuraman, S. \& Igbaria, M. (1990). An examination of gender differences in the determinants of computer anxiety and attitudes toward microcomputers among managers. International Journal of Man-Machine Studies, 32(3), 327-340.

Palmer, J. (2002). Website usability design and performance metrics. Information Systems Research, 13(2), 151-167.

Park, J., Yang, S., \& Lehto, X. (2007). Adoption of mobile technologies for Chinese consumers. Journal of Electronic Commerce Research, 8(3), 196-206.

Pavlou, P.A. \& Fygenson, M. (2006). Understanding and predicting electronic commerce adoption: An extension of the theory of planned behavior. MIS Quarterly, 30(1), 115-143.

PIB (2014). Press Information Bureau, Government of India. Accessed from http://pib.nic.in/newsite/erelease.aspx?relid=108926 on 25 ${ }^{\text {th }}$ September 2014.

Plouffe, C., Hulland, J., \& Vandenbosch, M. (2001). Research report: Richness versus parsimony in modeling technology adoption decisions - understanding merchant adoption of a smart card-based payment system. Information Systems Research, 12(2), 208-222.

Pynoo, B., Devolder. P., Tondeur, J., Van Braak, J., Duyck, W., \& Duyck, P. (2011). Predicting secondary school teachers' acceptance and use of a digital learning environment: A cross-sectional study. Computers in Human Behavior, 27(1), 568-575.

Rana, N.P. \& Dwivedi, Y.K. (2015). Citizen's adoption of an e-government system: Validating extended social cognitive theory (SCT). Government Information Quarterly, 32(2), 172-181.

Rana, N. P., Dwivedi, Y. K., Lal, B., Williams, M. D., \& Clement, M. (2015a). Citizens' adoption of an electronic government system: towards a unified view. Information Systems Frontiers, 1-20.

Rana, N.P., Dwivedi, Y.K., Williams, M.D., \& Weerakkody, V. (2015b). Investigating success of an e-government initiative: Validation of an integrated IS success model. Information Systems Frontiers, 17(1), 127-142.

Rana, N.P., Dwivedi, Y.K., Williams, M.D., \& Weerakkody, V. (2016). Adoption of online public grievance redressal system in India: Toward developing a unified view. Computers in Human Behavior, 59, 265-282.

Rogers, E.M. (1995). Diffusion of innovations. $4^{\text {th }}$ edition, New York, NY: Free Press. 
Ross, W. \& LaCroix, J. (1996). Multiple meanings of trust in negotiation theory and research: A literature review and integrative model. International Journal of Conflict Management, 7(4), 314-360.

Sambasivan, M., Wemyss, G.P., \& Rose, R.C. (2010). User acceptance of a G2B system: A case of electronic procurement system in Malaysia. Internet Research, 20(2), 169-187.

San Martín, H. \& Herrero, A. (2012). Influence of the user's psychological factors on the online purchase intention in rural tourism: Integrating innovativeness to the UTAUT framework. Tourism Management, 33(2), 341-350.

Schaper, L.K. \& Pervan, G.P. (2007). ICT and OTs: A model of information and communication technology acceptance and utilisation by occupational therapists. International Journal of Medical Informatics, 76S, S212-S221.

Schaupp, L.C. \& Carter, L. (2010). The impact of trust, risk and optimism bias on e-file adoption. Information Systems Frontiers, 12(3), 299-309.

Schaupp, L.C., Carter, L., \& McBride, M.E. (2010). E-file adoption: A study of U.S. taxpayers' intentions. Computers in Human Behavior, 26(4), 636-644.

Scott, J.K. (2006). "E" the people: Do US municipal government web sites support public involvement? Public Administration Review, 66(3), 341-353.

Segars, A.H. \& Grover, V. (1993). Re-examining perceived ease of use and usefulness: A confirmatory factor analysis. MIS Quarterly, 17(4), 517-525.

Simonson, M.R., Maurer, M., Montag-Torardi, M., \& Whitaker, M. (1987). Development of a standardized test of computer literacy and a computer anxiety index. Journal of Educational Computing Research, 3(2), 231-247.

Singh, A.K. \& Sahu, R. (2008). Integrating Internet, telephones, and call centers for delivering better quality e-governance to all citizens. Government Information Quarterly, 25(3), 477-490.

Srivastava, S. (2016). Guess how many people pay taxes in India. CNBC: Emerging Markets. Accessed from http://www.cnbc.com/2016/05/03/guess-how-many-people-pay-taxes-inindia.html on 18th October 2016

Steiger, J.H. \& Lind, J.C. (1980). Statistically-based tests for the number of common factors. Annual Spring Meeting of the Psychometric Society, Iowa City, 424-453.

Straub, D.W. \& Welke, R.J. (1998). Coping with systems risk: Security planning models for management decision making. Management Information Systems Quarterly, 22(4), 441-469.

Sulaiman, A., Jaafar, N.I. \& Aziz, N.A.A. (2012). Factors influencing intention to use MYEPF I-Akaun. World Applied Sciences Journal, 18(3), 451-461. 
Sumak, B., Polancic, G., \& Hericko, M. (2010). An empirical study of virtual learning environment adoption using UTAUT. Second International Conference on Mobile, Hybrid, and On-Line Learning, 17-22.

Susanto, T.D. \& Goodwin, R. (2011). User acceptance of SMS-based eGovernment services. In M. Janssen, H.J. Scholl, M.A. Wimmer, \& Y.-H. Tan (eds.). EGOV 2011, LNCS 6846, 7587.

Taheri, F. \& Mirghiasi, S.R. (2016). Presenting a typology of users satisfaction model from electronic government. International Academic Journal of Organizational Behavior and Human Resource Management, 3(4), 11-26.

Taylor, S. \& Todd, P.A. (1995a). Understanding information technology usage: A test of competing models. Information Systems Research, 6(2), 144-176.

Taylor, S. \& Todd, P.A. (1995b). Decomposition and crossover effects in the theory of planned behaviour: A study of consumer adoption. International Journal of Research in Marketing, 12(2), 137-155.

Teo, T.S. \& Liu, J. (2007). Consumer trust in e-commerce in the United States, Singapore and China. Omega, 35(1), 22-38.

Thompson, R.L., Higgins, C.A., \& Howell, J.M. (1991). Personal computing: Toward a conceptual model of utilization. MIS Quarterly, 15(1), 124-143.

Tolbert, C.J. \& Mossberger, K. (2006). The effects of e-government on trust and confidence in government. Public Administration Review, 66(3), 354-369.

Tornatzky, L. G., \& Klein, K. J. (1982). Innovation characteristics and innovation adoptionimplementation: A meta-analysis of findings. IEEE Transactions on Engineering Management, 29(1), 28-45.

Triandis, H.C. (1977). Interpersonal behavior. Monterey, CA: Brooke Cole.

Tung, L.L. \& Rieck, O. (2005). Adoption of electronic government services among business organizations in Singapore. Journal of Strategic Information Systems, 14(4), 417-440.

United Nations (2010). United Nations E-Government Survey 2010: Leveraging egovernment at a time of financial and economic crisis. New York, NY: Department of Economic and Social Affairs, United Nations.

Urumsah, D., Quaddus, M., \& Galbrieth, J. (2011). An investigation into the factors influencing consumers to use e-services of Indonesian airlines: The role of motivation. European Conference on Information Systems 2011 Proceedings, Helsinki, Finland.

Venkatesh, V. \& Davis, F.D. (2000). A theoretical extension of the technology acceptance model: Four longitudinal field studies. Management Science, 45(2), 186-204. 
Venkatesh, V., Chan, F.K., \& Thong, J.Y. (2012). Designing e-government services: Key service attributes and citizens' preference structures. Journal of Operations Management, 30(1), 116-133.

Venkatesh, V., Morris, M.G., Davis, G.B., \& Davis, F.D. (2003). User acceptance of information technology: Toward a unified view. MIS Quarterly, 27(3), 425-478.

Venkatesh, V., Thong, J.Y., \& Xu, X. (2012). Consumer acceptance and use of information technology: Extending the unified theory of acceptance and use of technology. MIS Quarterly, 36(1), 157-178.

Venkatesh, V., Thong, J.Y., Chan, F.K., Hu, P.J.H., \& Brown, S.A. (2011). Extending the two-stage information systems continuance model: Incorporating UTAUT predictors and the role of context. Information Systems Journal, 21(6), 527-555.

Wang, Y.-S. \& Liao, Y.-W. (2008). Assessing eGovernment systems success: A validation of the DeLone and McLean model of information systems success. Government Information Quarterly, 25(4), 717-733.

Wang, Y.-S. \& Shih, Y-W. (2009). Why do people use information kiosks: A validation of the unified theory of acceptance and use of technology. Government Information Quarterly, 26(1), 158-165.

Warkentin, M., Gefen, D., Pavlou, P.A., \& Rose, G.M. (2002). Encouraging citizen adoption of e-government by building trust. Electronic Markets, 12(3), 157-162.

Watson, R.T. \& Mundy, B. (2001). A strategic perspective of electronic democracy. Communications of the ACM, 44(1), 27-30.

Weerakkody, V., El-Haddadeh, R., Al-Sobhi, F., Shareef, M.A., \& Dwivedi, Y.K. (2013). Examining the influence of intermediaries in facilitating e-government adoption: An empirical investigation. International Journal of Information Management, 33(5), 716-725

West, D. (2004). E-government and the transformation of service delivery and citizen attitudes. Public Administration Review, 64(1), 15-27.

West, D.M. (2008). Improving technology utilization in electronic government around the world. Washington, DC: The Brookings Institution.

Yang, H.D. \& Yoo, Y. (2004). It's all about attitude: Revisiting the technology acceptance model. Decision Support Systems, 38(1), 19-31.

Yeow, P.H. \& Loo, W.H. (2009). Acceptability of ATM and transit applications embedded in multipurpose smart identity card: An exploratory study in Malaysia. International Journal of Electronic Government Research, 5(2), 37-56.

Zhang, N., Guo, X., \& Chen, G. (2011). Why adoption and use behavior of IT/IS cannot last? - Two studies in China. Information Systems Frontiers, 13(3), 381-395. 
Zhang, W. \& Gutierrez, O. (2007). Information technology acceptance in the social services sector context: An exploration. Social Work, 52(3), 221-231.

Zhang, X. \& Maruping, L. (2008). Household technology adoption in a global marketplace: Incorporating the role of espoused cultural values. Information Systems Frontiers, 10(4), 403413.

Zikmund, W.G. (1994). Business research methods. $4^{\text {th }}$ edition New York, NY: The Dryden Press. 


\section{Appendix A}

Respondents were asked the following questions on a Likert scale (1-7), where $1=$ extremely disagree and 7=extremely agree:

(Legend: AF: affect (Compeau \& Higgins, 1995a; Compeau et al., 1999); AT: attitude (Davis et al., 1989; Fishbein \& Ajzen, 1991); BI: behavioral intention (Venkatesh et al., 2003); CLX: complexity (Thompson et al., 1991); EOU: perceived ease of use (Davis, 1989; Davis et al., 1989; Moore \& Benbasat, 1991); EU: ease of use (Davis, 1989; Davis et al., 1989; Moore \& Benbasat, 1991); FC: facilitating conditions (Thompson et al., 1991); IMG: image (Moore \& Benbasat, 1991; Venkatesh \& Davis, 2000); OE: outcome expectation (Compeau \& Higgins, 1995a; Compeau et al., 1999); PBC: perceived behavioral control (Ajzen, 1991; Taylor \& Todd, 1995a, 1995b); PR: perceived risk (Cases, 2002; Colesca, 2009); PU: perceived usefulness (Davis, 1989; Davis et al., 1989; Moore \& Benbasat, 1991); RA: relative advantage (Davis, 1989; Davis et al., 1989; Moore \& Benbasat, 1991); SF: social factor (Venkatesh et al., 2003); SN: subjective norm (Ajzen, 1991; Fishbein \& Ajzen, 1975))

AT1. Using the OPCRS would be a good idea

AT2. Using the OPCRS would be a wise idea

AT3. I like the idea of using the OPCRS

AT4. Using the OPCRS would be pleasant

AF1. I would like working with the OPCRS

AF2. I would look forward to those aspects that require me to use the OPCRS

AF3. Using the OPCRS would be interesting to me

AF4. If I started working with the OPCRS, I would find it hard to stop

SN1. People who influence my behavior think that I should use the OPCRS

SN2. People who are important to me think that I should use the OPCRS

SF1. I would use the OPCRS because of the type of people who use the system

SF2. The Income Tax Department is helpful in the use of the OPCRS

SF3. The designated income tax official would be very supportive of the use of the OPCRS

SF4. In general, the Income Tax Department would support the use of the OPCRS

IMG1. People who use the OPCRS would have more prestige than those who don't

IMG2. People who use the OPCRS would have a high profile

IMG3. Using the OPCRS is a status symbol

OE1. If I used the OPCRS, I would increase my effectiveness of working with the Internet

OE2. If I used the OPCRS, I would spend less time on routine tasks

OE3. If I used the OPCRS, I would increase my quality of output

OE4. If I used the OPCRS, I would increase my quantity of output for the same amount of effort

OE5. If I used the OPCRS, my friends/colleagues would perceive me as competent

OE6. If I used the OPCRS, I would increase my chances of receiving honor in my society (or promotion)

OE7. If I used the OPCRS, I would increase my chances of getting recognized (or a raise in my job)

EU4/EOU1. Learning to operate the OPCRS would be easy for me 
EU2/EOU2. I would find it easy to get the OPCRS to do what I want it to do

EU1/EOU3. My interaction with the OPCRS would be clear and understandable

EOU4. I would find the OPCRS flexible to interact with

EOU5. It would be easy for me to become skillful at using the OPCRS

EU3/EOU6. I would find the OPCRS easy to use

RA1/PU1. Using the OPCRS would enable me to accomplish tasks quicker

PU2. Using the OPCRS would improve my overall performance

RA5/PU3. Using the OPCRS would increase my productivity

RA4/PU4. Using the OPCRS would enhance my effectiveness

RA3/PU5. Using the OPCRS would make it easier to get my PAN card done

PU6. I would find the OPCRS useful for obtaining my PAN card

RA2. Using the OPCRS would improve the quality of the work I do

PBC1. I would have command over using the OPCRS

PBC2. I would have the resources necessary to use the OPCRS

PBC3. I would have the knowledge necessary to use the OPCRS

PBC4. Given the resources, opportunities and knowledge, it would be easy for me to use this system

PBC5. The OPCRS would be compatible with the other systems I use

FC1. Guidance would be available to me in the use of the OPCRS

FC2. Specialized instruction concerning the OPCRS would be available to me

FC3. A specific person (or group) would be available for assistance with OPCRS difficulties

CLX1. Using the OPCRS would take too much time from my normal duties

CLX2. Working with the OPCRS would be so complicated that it would be difficult to understand what was going on

CLX3. Using the OPCRS would involve too much time doing mechanical operations

CLX4. It would take too long to learn how to use the OPCRS to make it worth the effort

PR1. Use of OPCRS may cause my personal information to be stolen

PR2. I would feel uneasy psychologically if I used the OPCRS

PR3. I think that it is unsafe to use the OPCRS because of the privacy and security concerns

PR4. I believe that there could be negative consequences by using the OPCRS

BI1. I intend to use the OPCRS

BI2. I predict that I will use the OPCRS

BI3. I plan to use the OPCRS in the near future 